\title{
Functionalized carbon nanotubes as suitable scaffold materials for proliferation and differentiation of canine mesenchymal stem cells
}

This article was published in the following Dove Press journal:

International Journal of Nanomedicine

19 April 2017

Number of times this article has been viewed

\author{
Kinsuk Das' \\ AP Madhusoodan' \\ Bhabesh Mili' \\ Ajay Kumar ${ }^{2}$ \\ AC Saxena ${ }^{3}$ \\ Kuldeep Kumar ${ }^{1}$ \\ Mihir Sarkar' \\ Praveen Singh ${ }^{4}$ \\ Sameer Srivastava ${ }^{5}$ \\ Sadhan Bag' \\ 'Division of Physiology and \\ Climatology, ${ }^{2}$ Biochemistry and Food \\ Science Section, ${ }^{3}$ Division of Surgery, \\ ${ }^{4}$ Biophysics, Electron Microscopy and \\ Instrumentation Section, ${ }^{5}$ Division \\ of Veterinary Biotechnology, Indian \\ Council of Agricultural Research - \\ Indian Veterinary Research Institute, \\ Izatnagar, Bareilly, Uttar Pradesh, India
}

Correspondence: Sadhan Bag Division of Physiology and Climatology, Indian Council of Agricultural Research - Indian Veterinary Research Institute, Izatnagar, Bareilly, Uttar Pradesh 243122, India

Tel+9l 9457708836

Email bag658@gmail.com
Abstract: In the field of regenerative medicine, numerous potential applications of mesenchymal stem cells (MSCs) can be envisaged, due to their ability to differentiate into a range of tissues on the basis of the substrate on which they grow. With the advances in nanotechnology, carbon nanotubes (CNTs) have been widely explored for use as cell culture substrate in tissue engineering applications. In this study, canine bone marrow-derived MSCs were considered as the cellular model for an in vitro study to elucidate the collective cellular processes, using three different varieties of thin films of functionalized carbon nanotubes ( $\mathrm{COOH}$-single-walled CNTs [SWCNTs], COOH-multiwalled CNTs [MWCNTs] and polyethylene glycol [PEG]-SWCNTs), which were spray dried onto preheated cover slips. Cells spread out better on the CNT films, resulting in higher cell surface area and occurrence of filopodia, with parallel orientation of stress fiber bundles. Canine MSCs proliferated at a slower rate on all types of CNT substrates compared to the control, but no decline in cell number was noticed during the study period. Expression of apoptosis-associated genes decreased on the CNT substrates as time progressed. On flow cytometry after AnnexinV-fluorescein isothiocyanate/propidium iodide (PI) staining, total number of apoptotic and necrotic cells remained lower in $\mathrm{COOH}$-functionalized films compared to PEG-functionalized ones. Collectively, these results indicate that COOH-MWCNT substrate provided an environment of low cytotoxicity. Canine MSCs were further induced to differentiate along osteogenic, chondrogenic, and neuronal lineages by culturing under specific differentiation conditions. The cytochemical and immunocytochemical staining results, as well as the expression of the bone marker genes, led us to hypothesize that the COOH-MWCNT substrate acted as a better cue, accelerating the osteogenic differentiation process. However, while chondrogenesis was promoted by $\mathrm{COOH}-\mathrm{SWCNT}$, neuronal differentiation was promoted by both $\mathrm{COOH}-\mathrm{SWNCT}$ and $\mathrm{COOH}-\mathrm{MWCNT}$. Taken together, these findings suggest that $\mathrm{COOH}$-functionalized CNTs represent a promising scaffold component for future utilization in the selective differentiation of canine MSCs in regenerative medicine.

Keywords: canine MSCs, CNT films, cellular behavior, cytocompatibility, differentiation

\section{Introduction}

The advantage of self-renewability and the unique characteristics of stem cells associated with differentiation, regeneration, remodeling, and replacement of diseased tissues make them perfect candidates for use in regenerative medicine. Recently, mesenchymal stem cells (MSCs) isolated from diverse sources ${ }^{1-3}$ have been considered to be one of the best choices of stem cells for cell-based tissue engineering.

The interaction of stem cells with their adjacent microenvironment is the basic element of all cellular processes. ${ }^{4}$ Properties of the in vitro cell culture substrate provide 
a dynamic microenvironment as well as the morphological cues suitable for stem cell proliferation and differentiation. The most novel protocols of stem cell culture are based on culturing the cells on polystyrene-coated plastic surfaces in the presence of suitable media. These culture conditions are different from the $3 \mathrm{D}$ niche that stem cells occupy in the body, a soft microenvironment formed by different components including the extracellular matrix (ECM) (along with its mechanical properties), cell-cell interactions, and secreted factors. Advances in nanotechnology have yielded synthetic bioinspired materials that create new controllable microenvironments for stem cell growth, proliferation, and lineagespecific directed differentiation. ${ }^{5,6}$ Carbon nanotube (CNT), an allotropic form of carbon, is becoming an increasingly attractive material as it can be modified by functionalization and used as scaffold material for promoting tissue regeneration and stem cell therapy because of its remarkable mechanical, optical and electrical properties. ${ }^{7-10}$ Recently, it has been shown that CNT-based scaffolds promote the proliferation and lineagespecific differentiation of human and rat MSCs. ${ }^{11-19}$ Successful differentiation studies of human embryonic stem cells have also been carried out using CNTs as scaffold materials. ${ }^{20-22}$ CNTs are also currently being used in other biomedical applications, such as cell tracking and labeling, nanosensors, and controlled delivery of drugs and bioactive agents. ${ }^{23,24}$

Physiologically and genomically, disease presentation, clinical symptoms and behavioral traits of the dog (Canis lupus familiaris) are more similar to those in humans compared to other animal models. ${ }^{25}$ A number of research reports have proven that dog is a potential animal model for clinical trials of human drugs, suggesting that this species could be a suitable model for experimentation in human regenerative medicine. ${ }^{26,27}$ Moreover, this species has gained a major role in veterinary medicine. Multipotent MSCs have been established from various canine-derived sources, such as adipose tissue, umbilical cord components, and bone marrow. ${ }^{28-33}$ The therapeutic potential of canine MSCs has also been established in veterinary medicine. ${ }^{34}$ Additionally, an advantage of using the canine model is the possibility of performing MSC transplantation in large-sized animals. ${ }^{30}$ Tissue engineering-based evaluations of different nanomaterials, such as nanomorphous calcium phosphate, hydroxyapatite, chitosan, and alginate hydrogel, have been carried out in canine models. ${ }^{35-38}$ However, very limited work has been conducted on the use of CNTs as scaffold components in canine models, such as the Madin-Darby Canine Kidney epithelial cell (MDCK) attachment study on multiwalled CNT (MWCNT)-incorporated poly $(N$-isopropylacrylamide) (PNIPAAM) hydrogel, primary canine chondrocyte proliferation on aerogel network of CNTs, and use of CNT-coated stent as delivery vehicle, to describe a few. ${ }^{39-41}$ The recent elucidation of accelerated in vitro osteogenesis of human preosteoblasts and murine ESCs on carboxylated CNT-coated coverslips followed by ectopic bone formation in a rat model has opened up the window of continuing further investigations on CNTs in other models. ${ }^{42}$

Considering the potential importance of CNTs as a scaffold material in human and veterinary medicine, it is necessary to achieve further development in the field and attain new knowledge. In this study, a population of cells has been isolated from canine bone marrow and characterized to confirm them as MSCs. These cells were cultured and made to differentiate in vitro on CNT thin film scaffolds prepared in the laboratory. This study provides fundamental information on the collective cellular behavior, cytocompatibility, and differentiation of canine bone marrow-derived MSCs on a CNT substrate. Our approach is therefore believed to demonstrate the possibility of utilizing the CNT substrate as a potential scaffold component for the proliferation and differentiation of canine MSCs, with the future perspective of an alternative cellular model in regenerative medicine.

\section{Materials and methods Isolation and characterization of canine MSCs}

Bone marrow was obtained aseptically from the iliac crest of healthy beagle dogs (Canis lupus familiaris) under anesthesia with informed consent of the owners and by following the safety compliances of the Institutional Animal Ethics Committee (IAEC) of the Indian Veterinary Research Institute, which has the approval of the Committee for the Purpose of Control and Supervision of Experiments on Animals (CPCSEA) under the Ministry of Environment, Forests and Climate Change, Government of India. The mononuclear cell fraction was isolated from red cells by density gradient centrifugation over Histopaque-1077 (Sigma, St Louis, MO, USA). The cells were plated at a density of $10^{5} \mathrm{cell} / \mathrm{s} / \mathrm{cm}^{2}$ in tissue culture flasks (Nunc, Germany) in Dulbecco's Modified Eagle's Medium (DMEM)-low glucose (LG) supplemented with $15 \%$ fetal bovine serum (FBS), L-glutamine ( $2 \mathrm{mM})$, penicillin $(100 \mathrm{U} / \mathrm{mL})$, streptomycin $(100 \mu \mathrm{g} / \mathrm{mL})$, and amphotericin B $\left(0.25 \mu \mathrm{g} / \mathrm{mL}\right.$ ) (all from Gibco, USA) at $37^{\circ} \mathrm{C}$ in a humidified atmosphere of $5 \% \mathrm{CO}_{2}$. Cells were serially passaged upon reaching $70 \%-80 \%$ confluence by detaching with $0.25 \%$ trypsin-ethylenediaminetetraacetic acid (EDTA) (Invitrogen, USA). Canine MSCs used in this study belonged to passage 4 . Cells were confirmed to meet the minimal 
criteria for defining multipotent MSCs by characterizing the morphology, plastic adherent property, immunophenotyping of pluripotency markers (octamer-binding transcription factor [Oct]3/4 and Nanog), MSC-specific surface markers (+ for cluster of differentiation [CD]73, CD90, and CD105 and - for CD45), and the ability for multiple-lineage differentiation in vitro.

\section{Fabrication and characterization of CNT thin films}

Carboxylic acid ( $\mathrm{COOH}-$ )-functionalized single-walled CNTs (SWCNTs) (Sisco Research Laboratory, India; diameter 1-2 nm, length 0.5-2 $\mu \mathrm{m}$ ), MWCNTs (Sigma, USA; diameter $9.5 \mathrm{~nm}$, length $1.5 \mu \mathrm{m}$ ), and polyethylene glycol (PEG)-functionalized SWCNTs (Sigma, USA; diameter 4-5 nm, length $0.5-0.6 \mu \mathrm{m})$ were dispersed separately in analytical grade ethanol $(0.1 \mathrm{wt} \%)$ using a probe sonicator (23 Hz) for 1 hour, followed by a bath sonicator $(40 \mathrm{~Hz}$ ) for 4 hours to ensure optimum homogeneity. The suspension was centrifuged at $800 \times g$ for 5 minutes to separate large agglomerates present, if any. Round coverslips (14 mm diameter) were precleaned with piranha solution, autoclaved, and preheated $\left(45^{\circ} \mathrm{C}\right)$ prior to preparing thin film scaffolds by spraying the homogenized suspension of CNTs onto the coverslips with an air brush. The scaffolds were allowed to air-dry and sterilized by ultraviolet (UV) irradiation prior to cell culture. For visualizing the surface topography of the scaffolds, we used field emission scanning electron microscopy (FESEM) (Carl Zeiss, Germany) at an accelerating voltage of $10 \mathrm{kV}$ with varying working distances and magnifications; and atomic force microscopy (AFM) (Park Systems, USA) using a silicon cantilever probe in tapping mode.

\section{Cellular behavior study \\ Cell spreading area}

Cells were seeded on control and CNT substrates at a low density and maintained in standard DMEM mentioned previously. Optical microscopic images were captured at regular intervals, and cell morphology was also studied. The spreading area of cells, chosen at random from different fields of each group, was measured using ImageJ software (National Institutes of Health).

\section{Scanning electron microscopy (SEM) of cell morphology}

High-resolution Electron Probe Microanalyzer (EPMA; Jeol, USA) was used to visualize the cellular morphology at the submicron level. CNT films with cells were fixed with $4 \%$
PFA for 1 hour followed by secondary fixation with $1.5 \%$ osmium tetroxide for 1 hour. Samples were then washed thoroughly in PBS and dehydrated in a graded ethanol series in a stepwise fashion $(30 \%, 50 \%, 70 \%, 90 \%, 95 \%$, and $100 \%$ for 15-30 minutes each) and subjected to critical point drying overnight using hexamethyldisilazane (HMDS) under a fume hood. Specimens were sputter-coated with gold-palladium and imaged at an accelerating voltage of $10 \mathrm{kV}$ at different magnifications.

\section{Immunocytochemical analysis}

Cells were seeded on control and CNT films at a low density and maintained in standard DMEM. On Day 4, the cultures were fixed with 4\% paraformaldehyde (PFA), washed in phosphate-buffered saline (PBS), permeabilized with $0.25 \%$ Triton X-100 in PBS, and blocked with $2 \%$ bovine serum albumin (BSA) for 1 hour. Cells were immunostained for filamentous actin filaments using Alexa Fluor ${ }^{\circledR} 680$ conjugated phalloidin (1:10; Invitrogen) overnight at room temperature, and after washing with PBS, the coverslips were mounted on glass slides with 4',6-diamidino-2-phenylindole (DAPI) ProLong ${ }^{\circledR}$ Gold antifade solution (Invitrogen). Images were captured using an inverted fluorescence microscope (Carl Zeiss) with Axio Vision 4.0 image analysis system.

\section{Studies on cytocompatibility of CNT films}

The cytocompatibility of the CNT substrates was assessed by three different experiments. Sterile CNT films were carefully placed inside 12-well tissue culture plates. Cells cultured in the wells without any films were considered as control. Standard DMEM was used to culture the MSCs at passage $4(\mathrm{P} 4)$ for all the experiments, and the plates were maintained for up to 6 days in an incubator at $37^{\circ} \mathrm{C}$ in a humidified atmosphere of $5 \% \mathrm{CO}_{2}$. Media were replaced on the third day of culture.

\section{Cell proliferation study}

Cells were seeded at a plating density of $1 \times 10^{4} / \mathrm{cm}^{2}$ on the control and CNT substrates. The number of metabolically active cells was determined by the 3-(4,5-dimethylthiazol-2-yl)2,5-diphenyltetrazolium bromide (MTT) assay (Invitrogen kit) on Days 2, 4, and 6 of culture as per the manufacturer's protocol. The experiment was done in triplicate.

\section{Relative expression of apoptosis-associated genes}

Total RNA was harvested from the cultured cells on Days 4 and 6 using TRIzol ${ }^{\circledR}$ reagent (Invitrogen) following 
the manufacturer's instructions. Total RNA was quantified, and the quality was ascertained (optical density [OD] 260/280>1.6) using NanoDrop (Eppendorf, USA). A total of $1 \mu \mathrm{g}$ RNA was reverse-transcribed to synthesize complementary DNA (cDNA) using iScript ${ }^{\mathrm{TM}}$ cDNA Synthesis Kit (Bio-Rad, USA). Reverse transcriptase-polymerase chain reaction (RT-PCR) and semiquantitative gene expression analysis was carried out using Real-Time PCR system (BioRad) with SsoFast ${ }^{\mathrm{TM}}$ EvaGreen ${ }^{\circledR}$ Supermix (Bio-Rad) and canine-specific primers (Table S1) for the apoptosis-associated genes Bcl-2-associated X protein $(B A X)$, Caspase-3 (CASP3), Caspase-8 (CASP8), and Caspase-9 (CASP9). The endogenous housekeeping control gene was considered as the glyceraldehyde 3-phosphate dehydrogenase (GAPDH).

The thermal cycling condition comprised an initial denaturation at $95^{\circ} \mathrm{C}\left(30\right.$ seconds), followed by 40 cycles at $95^{\circ} \mathrm{C}$ ( 5 seconds), annealing, and extension (temperature and duration variable for the different genes). Melting curves were generated at the end of 40 cycles to verify the purity of the PCR product. Each PCR product was size-fractionated by $2 \%$ agarose gel electrophoresis, and the bands were visualized with a UV transilluminator (Bio-Rad). Data were obtained as average cycle threshold $(C T)$ values and normalized against housekeeping control. Expression changes of different transcripts were measured as fold change with respect to cells cultured on control plate without any scaffolds using the method proposed by Pfaffl. ${ }^{43}$

\section{Annexin V-fluorescein isothiocyanate (FITC)/} propidium iodide $(\mathrm{PI})$ staining and flow cytometry Annexin V-FITC/PI Apoptosis Detection Kit (BioVision, USA) was used for the flow cytometry assay to quantify the apoptotic and necrotic cells on Days 4 and 6 of culture. This test was followed as per the manufacturer's instruction by flow cytometry (FACS Calibur; BD Biosciences, USA) using the FITC signal detector (FL1) and by PI staining using the phycoerythrin emission signal detector (FL2). Data were analyzed by recording 5,000 events with Cell Quest Pro software (BD Biosciences) (Figure S1A).

\section{In vitro differentiation of canine MSCs on CNT films}

Sterile CNT films were placed in 12-well tissue culture plates. Canine MSCs at P4 were cultured at a plating density of $5 \times 10^{3}$ cells $/ \mathrm{cm}^{2}$ and the culture wells without any film were considered as control. The culture plates were maintained in standard DMEM for 3 days in an incubator at $37^{\circ} \mathrm{C}$ in a humidified atmosphere of $5 \% \mathrm{CO}_{2}$ before changing into differentiation media. We denote the day when the cells were switched to differentiating medium as the Day 0 time point.

Osteogenic induction was accomplished using DMEM-LG (Gibco) supplemented with 10\% FBS (Gibco), $50 \mu \mathrm{g} / \mathrm{mL}$ ascorbic acid, $10 \mathrm{mM} \beta$-glycerophosphate, $10 \mathrm{nM}$ dexamethasone (all from Sigma), and antibiotics. Cells were cultured for 21 days, and the medium was changed every third day.

To promote chondrogenic differentiation, cells were incubated in media containing DMEM-LG (Gibco) supplemented with 10\% FBS (Gibco), $100 \mathrm{nM}$ dexamethasone, $50 \mu \mathrm{M}$ ascorbic acid-2 phosphate, $1 \mathrm{mM}$ sodium pyruvate, $10 \mathrm{ng} / \mathrm{mL}$ transforming growth factor beta 1 (TGF- $\beta 1$ ), $1 \%$ insulin, human transferrin, and insulin-transferrin-selenium (ITS) premix (all from Sigma), and antibiotics. The medium was changed every third day, and cells were maintained for 21 days.

For neuronal differentiation, cells were plated at a density of $1 \times 10^{5} / \mathrm{cm}^{2}$ and were maintained for up to 2 days in DMEM before changing into differentiation media. The differentiation protocol followed was as per Woodbury et al. ${ }^{44}$ Twenty-four hours prior to neuronal induction, the medium was replaced with preinduction medium containing DMEM-LG (Gibco), 20\% FBS (Gibco), and $1 \mathrm{mM}$ $\beta$-mercaptoethanol (BME, Sigma). To initiate neuronal differentiation, the medium was replaced with induction medium composed of DMEM-LG and $2 \mathrm{mM} \mathrm{BME}$ and maintained for another 6 days. Images were taken at different time points by a phase contrast microscope (Olympus, Japan).

\section{Cytochemical staining}

Cytochemical staining by Alizarin Red (0.2\% solution, $\mathrm{pH} 4$.1; Sigma) was carried out after 21 days of osteogenic differentiation by fixing cells with 4\% PFA for 30 minutes and staining for 1 hour at room temperature in darkness. Unbound stain was washed off with distilled water. Similarly, Alcian Blue staining (in 0.3\% acetic acid, pH 2.5; Sigma) was carried out after 21 days of chondrogenic differentiation by fixing the cells with 4\% PFA for 30 minutes and staining for 30 minutes at room temperature. Unbound stain was washed off with PBS. Accumulation of mineralized calcium nodules and blue-colored proteoglycan was visualized for osteogenesis and chondrogenesis, respectively, and imaged by a phase contrast microscope (Olympus).

\section{Relative expression of differentiation-associated genes}

Total RNA was extracted and cDNA was prepared from the samples on Days 14 and 21 for both osteogenic and chondrogenic differentiations, as well as 6 days after induction 
in the case of neuronal differentiation. RT-PCR and semiquantitative gene expression analysis for the respective differentiation process was carried out using the Real-Time PCR System (Bio-Rad) with canine-specific primers (Table S1) for the following: bone marker genes: osteocalcin $(O C N)$, osteopontin $(O P N)$, and collagen type I alpha 1 (Col IAI); chondrogenesis marker genes: collagen type II alpha 1 (Col 2A1), aggrecan (ACAN), and SRY-box 9 (SOX9); and neuronal marker genes: tubulin beta 3 class III (TUBB3), microtubule-associated protein $2(M A P 2)$, nestin (NES), and neural cell adhesion molecule (NCAM). The endogenous housekeeping control gene considered was GAPDH. Thermal cycling, generation of melting curves, and size-fractionation of PCR products were done as per previously mentioned protocols. Data were obtained as average $C \mathrm{~T}$ values and normalized against housekeeping control. Expression changes of different transcripts were measured as fold change with respect to cells differentiated on control plates without any scaffolds, using the method proposed by Pfaffl. ${ }^{43}$

\section{Immunocytochemical staining}

Immunocytochemistry was used to detect osteocalcin and aggrecan localization in control and scaffolds after 21 days of osteogenic and chondrogenic differentiations, respectively. Likewise, cells were also immunostained by neuralspecific markers $\beta$-III tubulin and MAP2 after 6 days of neuronal induction. Cells were fixed, permeabilized, and blocked as mentioned earlier and incubated with Alexa Fluor 488-conjugated rabbit polyclonal anti-osteocalcin (1:100; Biospes, China) overnight at $4{ }^{\circ} \mathrm{C}$. Similarly, overnight incubations at $4{ }^{\circ} \mathrm{C}$ with the antibodies rabbit polyclonal anti-aggrecan (1:100; Biospes), mouse monoclonal anti- $\beta$-III tubulin (1:100; Santa Cruz, USA), and mouse monoclonal anti-MAP2 (1:100; Santa Cruz) were followed by 4 hour incubation with iFluor ${ }^{\circledR}$ 488-conjugated anti-rabbit (1:200; Biospes), FITC-conjugated anti-mouse (1:200; Santa Cruz), and Alexa Fluor 594-conjugated anti-mouse (1:200; Invitrogen) secondary antibodies, respectively, at room temperature in darkness. After PBS washing, the coverslips were mounted on glass slides with DAPI ProLong Gold antifade solution (Invitrogen). All images were obtained using the same photographic parameters of exposure and speed in an inverted fluorescence microscope (Carl Zeiss) with Axio Vision 4.0 image analysis system.

\section{Flow cytometry assay}

Flow cytometry was done to determine the percentage of osteocalcin- and aggrecan-positive cells in the control and treatment groups after 21 days of osteogenic and chondrogenic differentiations, respectively, and $\beta$-III tubulin-positive cells after 6 days of neuronal induction. Cells were harvested and immunostained by incubation with the same set of antibodies used for immunocytochemistry, washed with PBS, and analyzed in flow cytometer (FACS Calibur, BD Biosciences). Instrument settings were established using unstained cells. Cells were gated by forward scatter to eliminate debris. To eliminate the possible autofluorescence of canine MSCs, the contribution of unstained cells was removed in FITC signal detector (FL1) channel. Data were analyzed by Cell Quest Pro software (BD Biosciences) (Figure S1B).

\section{Statistical analysis}

All quantitative cellular experiments were run in triplicate. Data were expressed as mean \pm standard error of the mean and analyzed with one-way analysis of variance (ANOVA), followed by Duncan's post hoc test (SPSS Inc, USA). Statistical significance was considered at $P<0.05$.

\section{Results and discussion Isolation and characterization of canine MSCs}

In this study, a population of cells was isolated from canine bone marrow and expanded in vitro. Approximately 4 days after seeding, cells started to attach to the polystyrene-coated plastic surface and proliferated. Initially, cells with differing morphologic features were observed in culture, consisting of loosely attached rounded cells and tightly attached spindle-shaped cells. During expansion, rounded cells were removed during washing and spindle-shaped cells became predominant, which further flattened to assume a fibroblastic appearance during third passage. Expanded cells in the fourth passage appeared morphologically homogeneous (Figure 1A). In immunocytochemical analysis, cells were positive for the pluripotency markers Oct 3/4 and Nanog, as well as the MSC-specific surface markers CD105, CD90, and CD73 (Figure 1B). Fluorescence-activated cell sorting (FACS) revealed that the cells were positive for CD105 (97.45\%), CD90 (93.46\%), and CD73 (97.70\%). In contrast, the majority of the cells were negative for the hematopoietic cell marker CD45 (0.46\%), indicating that the cells of hematopoietic origin had been debarred at the time of the cell expansion process (Figure 1C). Cells were able to differentiate to osteocytes, chondrocytes, and adipocytes under standard in vitro differentiating conditions. Osteogenic differentiation was confirmed after 21 days by Alizarin staining, which showed prominent mineralized nodules on the 
A

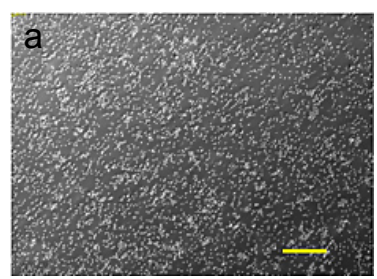

C
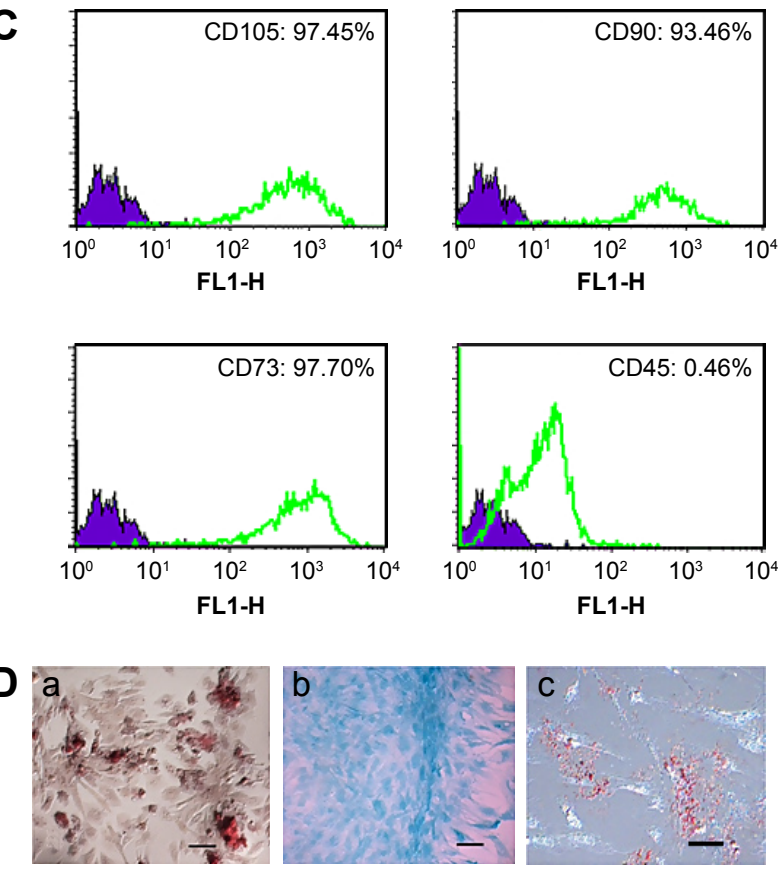

B
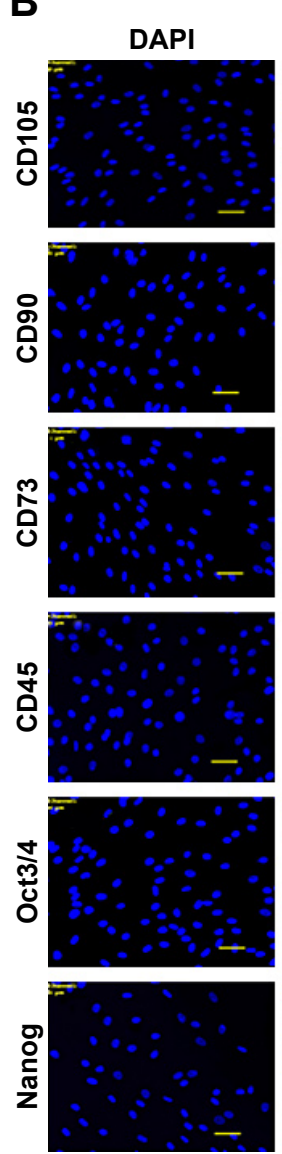

Alexa Fluor ${ }^{\circledR}$ 488/594
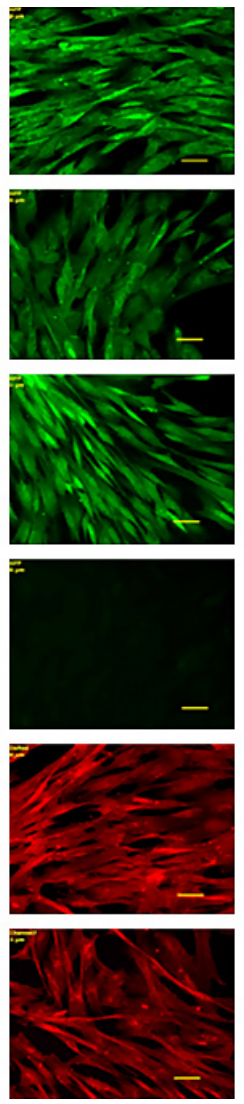

Merge
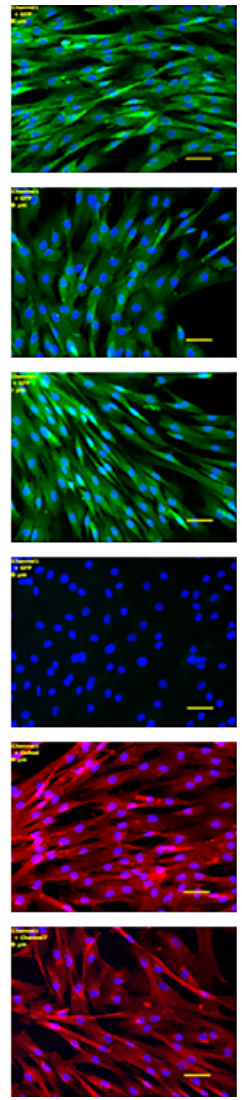

Figure I Characterization of canine bone marrow-derived MSCs.

Notes: (A) Morphology of canine MSCs. (a) P0 after seeding and (b) P4 in confluence; scale bar: $100 \mu \mathrm{m}$ (inset: $50 \mu \mathrm{m}$ ). (B) Immunofluorescence staining of MSC-specific surface markers (positive for CDI05, CD90, and CD73 and negative for CD45) and pluripotency markers (Oct3/4, Nanog). Scale bar: $50 \mu \mathrm{m}$. (C) Immunophenotyping of canine MSCs at P4. Values represent the mean percentage of positively stained cells as analyzed by flow cytometry. (D) Potential of canine MSCs to differentiate into mesodermal lineages. (a) osteocytes (Alizarin Red staining), (b) chondrocytes (Alcian Blue staining), and (c) adipocytes (Oil Red O staining). Scale bar: $50 \mu m$.

Abbreviations: CD, cluster of differentiation; DAPI, 4',6-diamidino-2-phenylindole; MSC, mesenchymal stem cell; Nanog, unique homeobox transcription factor; Oct, octamer-binding transcription factor; $\mathrm{PO} / 4$, passage $0 / 4$.

culture substrate. Accumulation of proteoglycan was noticed by Alcian Blue staining after 21 days of chondrogenic differentiation. After 21 days, the lipid vacuoles in the adipogenic differentiated cells were stained red by Oil Red O staining (Figure 1D). Therefore, the cell population used in this study meets the minimal criteria to define multipotent MSCs.

\section{Characterization of CNT thin films}

The physical appearance of all three varieties of CNT thin film scaffolds was observed by FESEM and AFM (Figure 2). The deposited CNTs formed a continuous mesh-like network over the coverslips. In higher magnification, it was found that the individual COOH-MWCNT bundles were well defined and formed a more uniformly homogeneous network throughout the coverslip, whereas the COOH-SWCNT and PEG-SWCNT bundles were not well separated and uniformly spread out.

\section{Cellular behavior study}

SEM and AFM images revealed that we were able to create nanoroughness or a nanofeature available for the cells to interact at the cell-material interface. To identify the effect of CNT topography on canine MSCs, different cellular behaviors such as the cell spreading area, morphological analysis, as well as cytoskeleton orientation were evaluated.

After seeding, the cells got attached and spread eventually in both control and CNT films, maintaining the fibroblastic morphology of MSCs (Figure 3A). After 4 days of culture, the cells on the CNT films became more spread out and exhibited elongated morphology composed of longer cytoplasmic projections visible with bright field microscopy, whereas the control displayed more polygonal morphology (Figure 3B). High-resolution SEM was conducted for better visualization of the morphological changes at the submicron level. The cells cultured on the untreated coverslips showed a less well-spread 


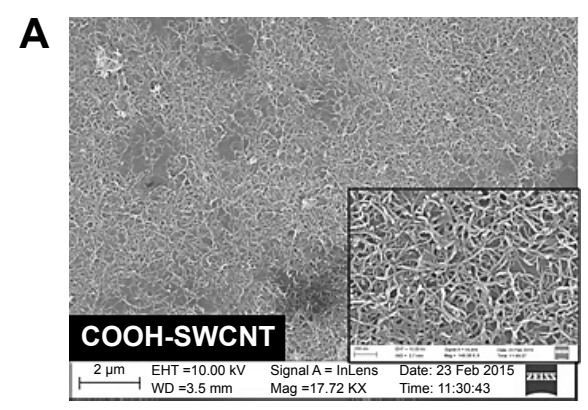

B

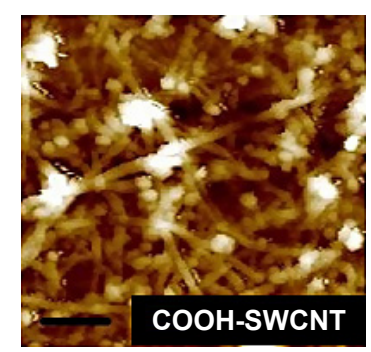

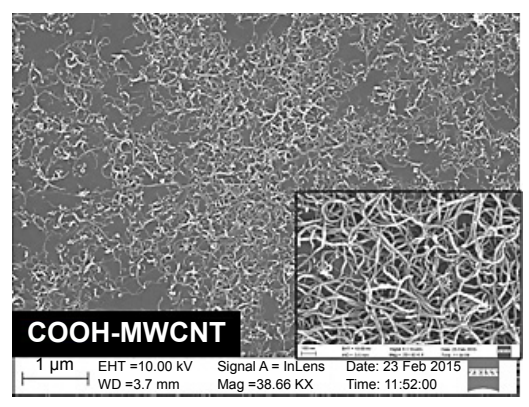

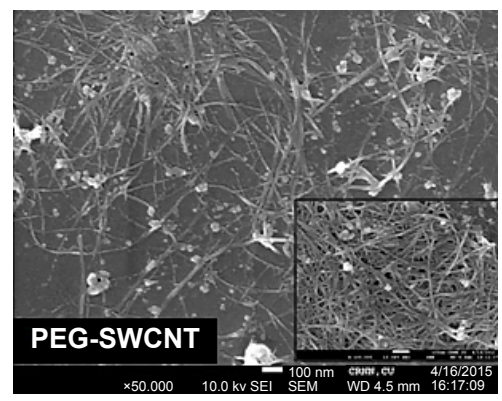

Topography - trace - main - flatten

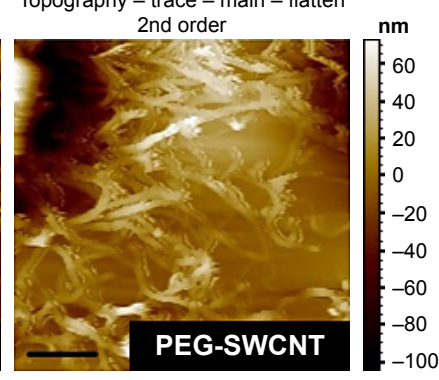

Figure 2 Characterization of CNT thin films.

Notes: (A) FESEM images (inset: higher magnification); (B) AFM images (horizontal scale bar: $400 \mathrm{~nm}$ ) of three types of CNT films.

Abbreviations: AFM, atomic force microscopy; CNT, carbon nanotube; FESEM, field emission scanning electron microscopy; MWCNT, multiwalled CNT; PEG, polyethylene glycol; SWCNT, single-walled CNT.
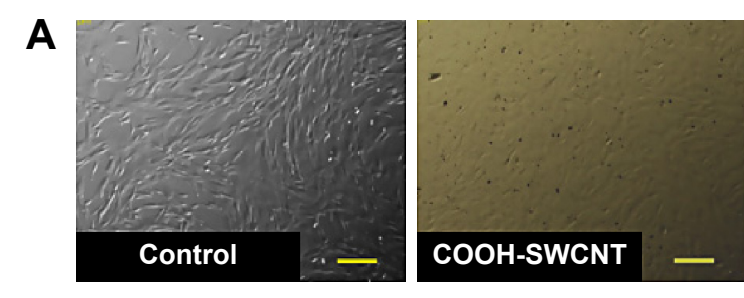

B
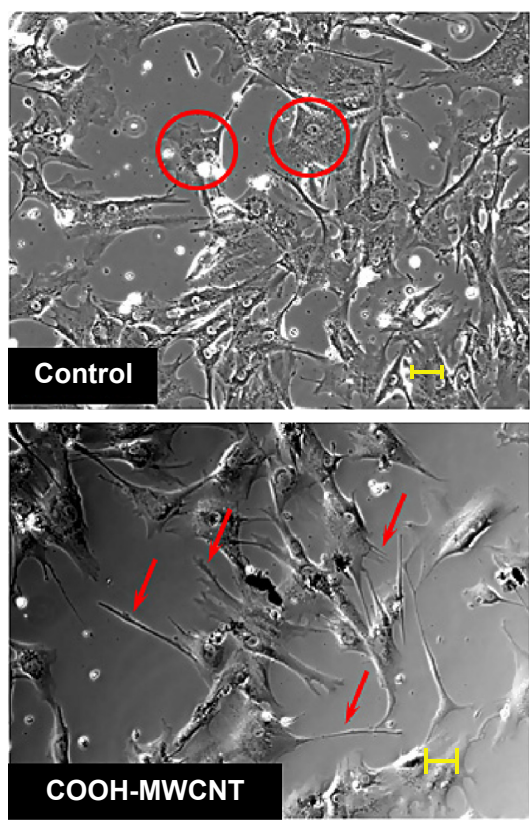
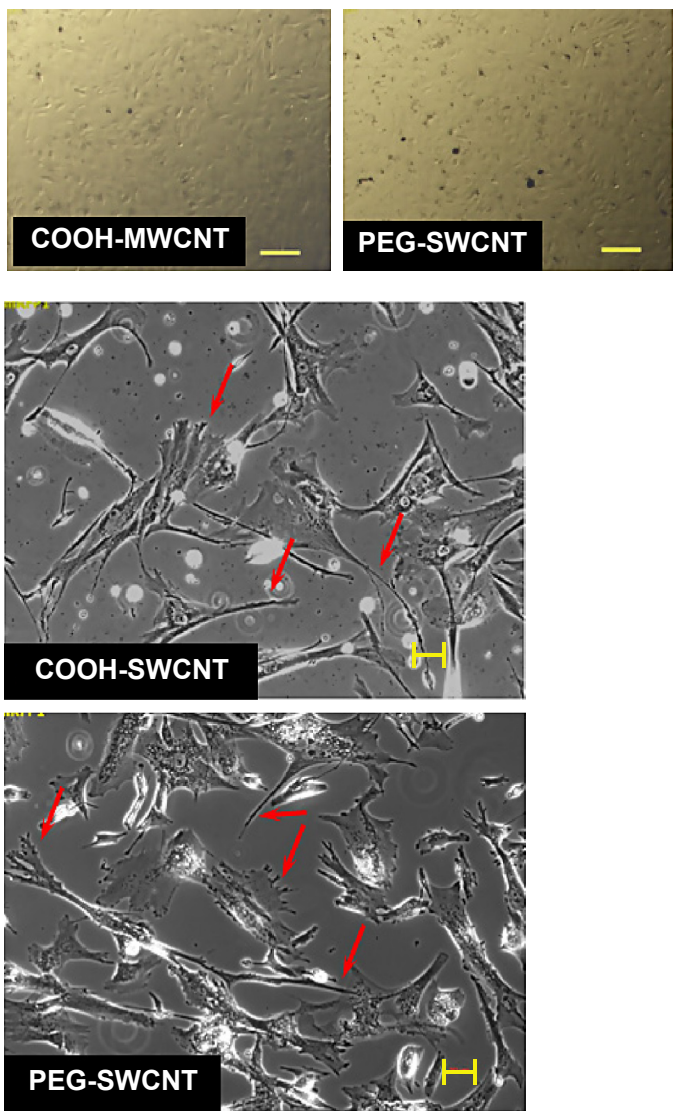

Figure 3 Canine MSCs cultured on CNT films.

Notes: (A) Phase contrast light microscopy images of confluent P4 cells on control and CNT films. Scale bars: $100 \mu \mathrm{m}$. (B) Bright field images of subconfluent P4 cells on control and CNT films. Scale bars: $50 \mu \mathrm{m}$. Cells in control show more polygonal morphology (circles), while cells exhibited more elongated morphology with subcellular features of longer lamellipodia and filopodia (arrows) on the CNT substrates.

Abbreviations: CNT, carbon nanotube; MWCNT, multiwalled CNT; SWCNT, single-walled CNT; MSCs, mesenchymal stem cells; P4, passage 4; PEG, polyethylene glycol. 
morphology than those on CNT films. Images at higher magnification confirmed the higher and more elongated occurrence of protrusive subcellular features on CNT films. In the case of control samples, the cell edge was characterized with less abundance of cytoplasmic projections and the presence of lamellipodia, in contrast to the extensive formation of filopodia on the cells over CNT films (Figure 4A). The result from the cell spreading area determination was found to be in accordance with our morphological analysis. Cells cultured over CNT substrates exhibited larger spreading area compared to the control up to Day 4 (Figure 4B). This might be due to the difference in the development of the focal adhesion points and cytoskeleton caused by the CNT network on the culture substrate. However, the difference in cell spreading area was reduced by Day 6 of culture, which might be the consequence of the confluence of cells on both the substrates due to the natural progression of mitotic division resulting in contact inhibition. ${ }^{11}$

There are two forms of the actin machinery coexisting at the leading edge of most of the motile cells. Lamellipodia are designed for the persistent protrusion over a surface and form new cellular contacts, whereas filopodia are considered as the major sensory and exploratory tool in probing nanofeatures depending on cues of the environment. ${ }^{45}$ Human
A

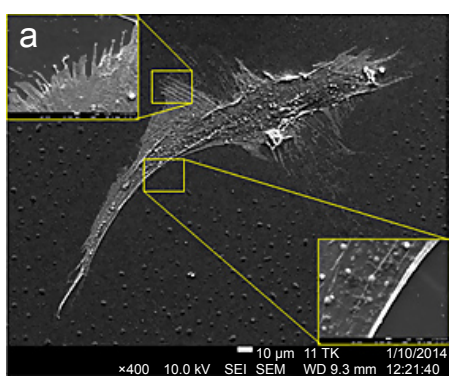

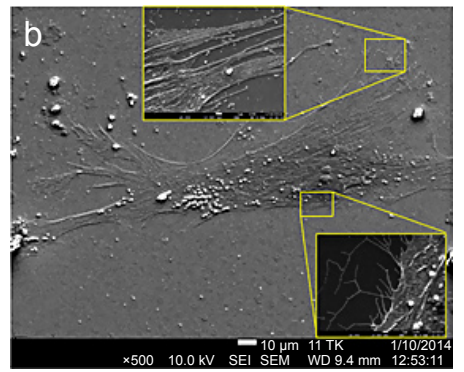

C
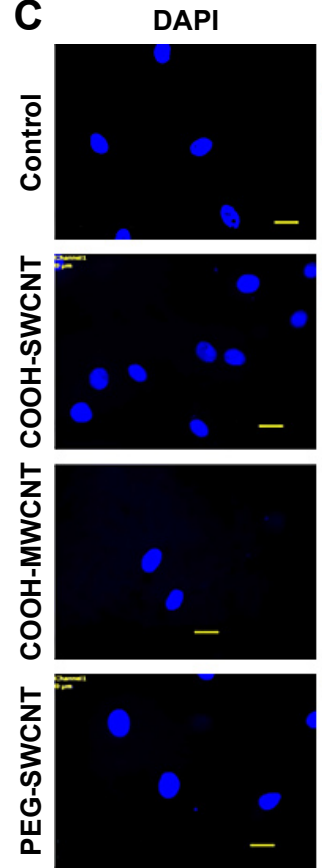

Alexa Fluor ${ }^{\circledR} 680$ phalloidin
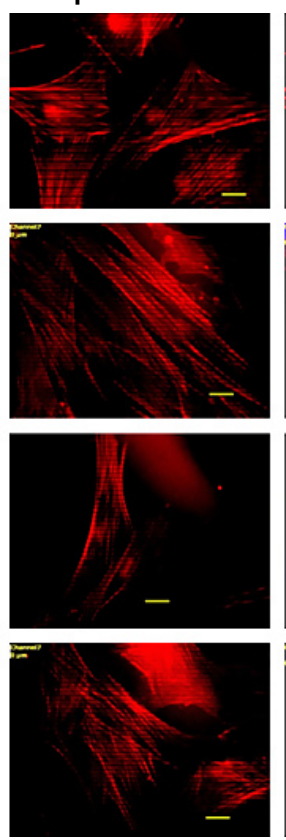
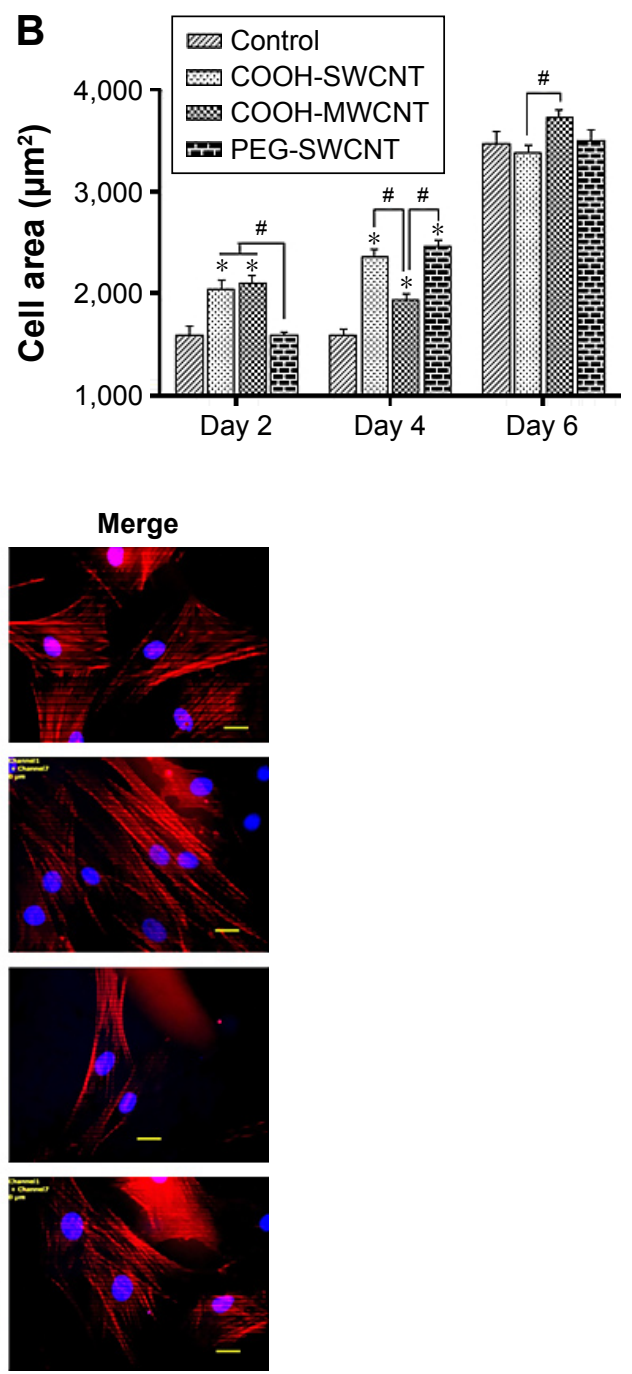

Figure 4 Cellular behavior on CNT substrates.

Notes: (A) SEM observation of canine MSCs on (a) control and (b) CNT films after 4 days of culture. Insets show the magnified view of the cell boundary. In the control, cytoplasmic projections were less abundant and presence of lamellipodia at the edges of cells was visualized. In CNT film, a higher occurrence of nanosized filopodia suggests that CNT substrate exerts its influence on canine MSC morphology. (B) Cell spreading area on control and CNT films at different time intervals. The symbols * and \# indicate significance $(P<0.05)$ with respect to control and between the films, respectively, on a particular day. The results are the mean \pm standard error of the mean of triplicate experiments $(n=30)$. (C) Alexa Fluor 680-conjugated phalloidin-labeled F-actin (red), DAPI nuclear staining (blue), and merged fluorescence images of immunostained cellular components of canine MSCs cultured on control and different CNT films on Day 4. Scale bars: $20 \mu \mathrm{m}$.

Abbreviations: CNT, carbon nanotube; DAPI, 4',6-diamidino-2-phenylindole; MSC, mesenchymal stem cell; MWCNT, multiwalled CNT; PEG, polyethylene glycol; SEM, scanning electron microscopy; SWCNT, single-walled CNT. 
MSCs cultured over a thin film of CNTs showed the influence of CNTs on cellular morphology, with evidence of thin filopodial projection with better cell spreading. ${ }^{11,46}$ In our FESEM imaging, distinctly evidenced filopodia in the cells justified the availability of a nanoscale 3D surface for better cell spreading over the films, which correlates with the result of cell spreading area, wherein we found a significantly higher cell spreading area on CNT substrates. It has also been reported that cellular spreading is a critical factor for stem cell differentiation through mechanotransduction. ${ }^{46,47}$ In the next phase of our study, we noticed an enhanced differentiation of canine MSCs, which is assumed to be a consequence of surface-guided favorable cue leading to better cell spreading.

Immunocytochemical analysis was done to visualize the expression of F-actin cytoskeleton assembly. After culturing for 4 days, development of stress fiber bundles became more distinct, and these had parallel orientation with respect to each other in the cells of treatment groups compared to the control (Figure 4C). More prominent stress fibers visible on the films might be an indication of the cells' attempt to adapt to this nanoroughness of the rigid surface for better adhesion. Because of the biochemical and mechanical interactions between the cells and their environment, stress fiber abundance, structure, and organization are modulated; and cells assemble stress fibers when they encounter mechanical stress and/or force. ${ }^{48}$ As the cytoskeletons are designed principally to reinforce the cells against mechanical deformation, we speculate that the parallel entanglement of the actin filament network was formed to resist additional deformation of cells on the CNT substrates. ${ }^{49}$ From our overall observation, we hypothesize that stabilization of the submicron-level cellular processes such as filopodia as well as an organized orientation of stress filaments occurred when canine MSCs encountered a favorable topographical cue of CNT films.

\section{Cytocompatibility of CNT films}

The proliferative property of canine MSCs at various time points was determined by the MTT assay (Figure 5A). Increment of cell number at a steady level was noticed on the control and different films. However, canine MSCs proliferated at a slower rate on all types of CNT substrates compared to control. Cells on MWCNT film proliferated in a better way compared to SWCNT and PEG-SWCNT, and a nonsignificant difference was noticed at Day 6 with respect to control. Reduced rate of proliferation of stem cells from different origins and species is rather common on CNT substrates. ${ }^{11,12,18,20}$ Cells cultured on non-arranged CNT films may require more energy to adapt to the substrate; hence, this could reduce the cell proliferation rate..$^{50,51} \mathrm{We}$ suggest that the non-arranged environment of CNTs in these spraycoated thin films might be one of the factors for the reduced proliferation rate. We also speculate an early initiation of the differentiation process in these cells because hMSCs have been reported to show a reduced proliferation rate during the differentiation process on synthetic nanostructures as well as on CNT substrate. ${ }^{46,52}$ Although the rate of proliferation was slow, we could not find any decline of cell number over the study period, indicating that CNTs do not have profound toxic effect on canine MSCs.

In gene expression study, the relative expression of $B A X$ was higher at the initial stage of the experiment but decreased later on; it was found to be significant in the PEGSWCNT group. Initially, the relative expression of CASP9 was significantly higher on all the CNT substrates but this was sustained till Day 6 only on COOH-SWCNT. Among the other apoptotic genes, the relative expression of $C A S P 8$ and $C A S P 3$ was never noticed to be significantly different on $\mathrm{COOH}$-functionalized CNT films compared to control, whereas expression of these genes was always found to be moderately higher on PEG-SWCNT substrate. It is imperative to note that all these genes' expression level decreased on the CNT substrates as time progressed (Figure 5B). Caspases are a family of genes important for maintaining homeostasis through regulating cell death. Extrinsic apoptosis pathway is triggered by extracellular cues that activate CASP 8 and, subsequently, the executioner $C A S P 3$, whereas the intrinsic pathway is mediated through $C A S P 9$ by the mitochondrial apoptosome. ${ }^{53}$ In this study, upregulation of CASP 8 was found to be nonsignificant on the scaffolds, indicating that the nanotopography did not influence the extrinsic pathway of apoptosis. The CASP9 pathway is basically activated by a vast array of cellular stresses. ${ }^{53}$ The higher expression of CASP9 on Day 4 might be due to the stress that the cells were handling while adapting to the surface or due to the internalization of CNTs. ${ }^{13}$ However, the expression level was reduced to a nonsignificant level on Day 6 on MWCNT films. It is also important to note that the expression of the executioner caspase, ie, CASP3, was always found to be nonsignificant compared to control, and that $B A X$ expression was significantly reduced on MWCNT substrates at the later stages. We suggest that there might be some cellular antiapoptotic factors coactivated in this nanomaterial-based substrate culture system.

The extent of apoptosis was also evaluated by the quantification of apoptotic and necrotic cells by Annexin V-PI 

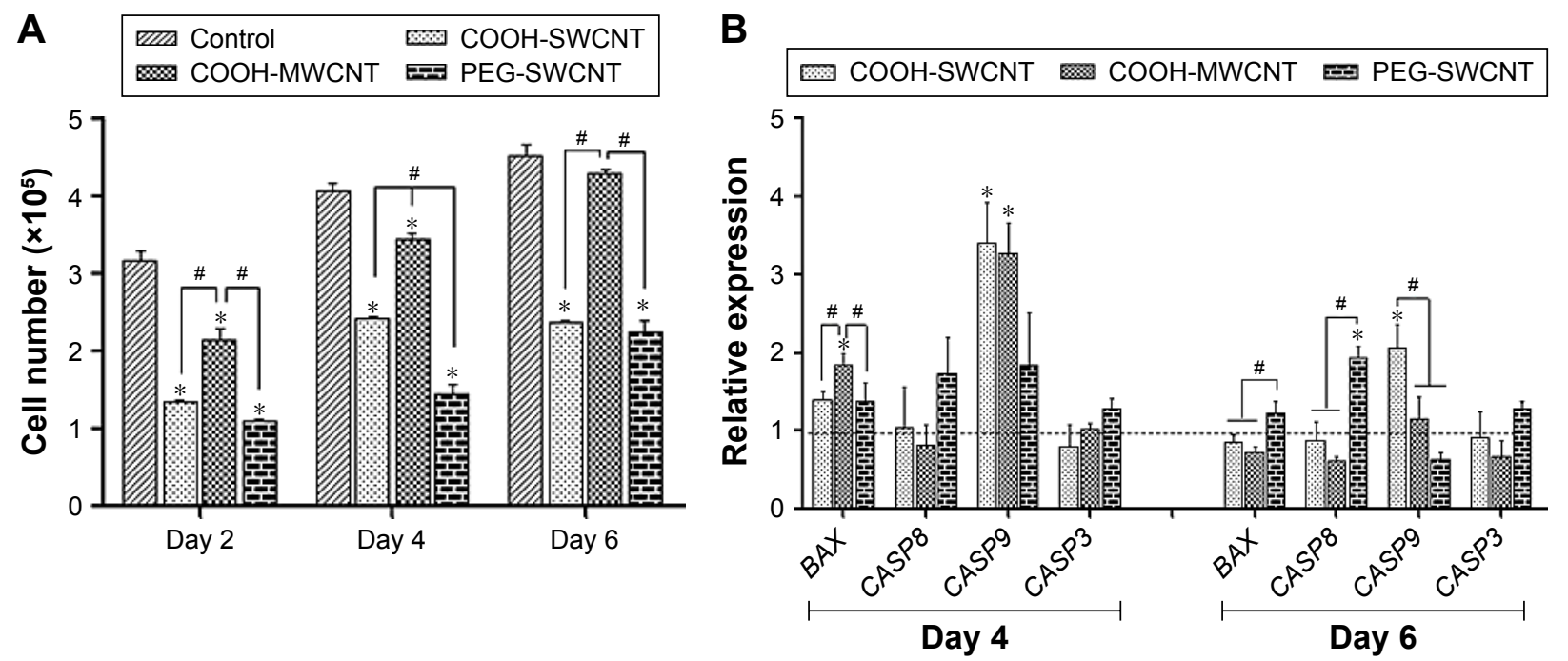
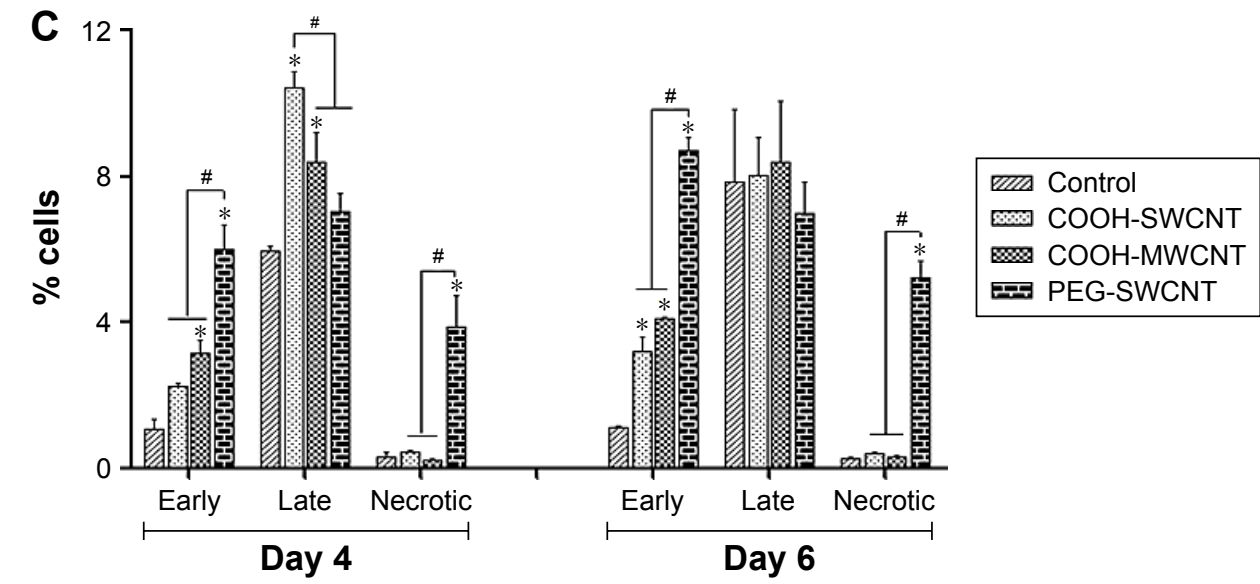

Figure 5 Cytocompatibility of CNT films.

Notes: (A) Cell proliferation assay (MTT assay) of canine MSCs cultured on control and different CNT films up to Day 6 . The symbols * and ${ }^{\#}$ indicate significance $(P<0.05)$ with respect to control and between the films, respectively, on a particular day. The results are the mean \pm standard error of the mean of triplicate experiments. (B) Relative expression of apoptosis-associated genes in canine MSCs cultured on control and different CNT films. Results normalized to GAPDH relative to control. Dashed line indicates values of target genes in control conditions. The symbols * and \# indicate significance $(P<0.05)$ with respect to control and between the films, respectively, for a target gene. (C) Flow cytometry assay of early apoptotic, late apoptotic, and necrotic canine MSCs (percentage of cells) cultured on control and different CNT films for a period up to 6 days. The symbols * and \# indicate significance $(P<0.05)$ with respect to control and between the films, respectively, at an individual stage of apoptosis on a particular day. Abbreviations: CNT, carbon nanotube; GAPDH, glyceraldehyde 3-phosphate dehydrogenase; MSC, mesenchymal stem cell; MTT, 3-(4,5-dimethylthiazol-2-yl)-2, 5-diphenyltetrazolium bromide; MWCNT, multiwalled CNT; PEG, polyethylene glycol; SWCNT, single-walled CNT.

flow cytometry assay up to 6 days of culture. The result of this assay showed that the numbers of apoptotic and necrotic cells were always higher on the CNT substrates compared to control. However, it is essential to note that the total number of apoptotic and necrotic cells remained $<14 \%$ and few cells $(<1 \%)$ became necrotic irrespective of $\mathrm{COOH}$-functionalization of CNT films. But, these quantities were noticed to be quite high in the PEG-functionalized group (Figure 5C). As evidenced in FESEM, less separation and nonuniformity of PEG-SWCNT bundles might be responsible such higher cell necrosis.

Similar to other nanomaterials, CNTs are rapidly approaching their targeted clinical use. However, it is difficult to broadly classify CNTs as "nontoxic" or "toxic" because their effects on cells are highly dependent on the application and cell type.${ }^{54}$ In previous studies by Mooney et al, ${ }^{13}$ it has been shown that CNTs were less toxic when dispersed in hMSCs culture media and it was correlated by the authors with a similar study by Chin et al,${ }^{55}$ who worked on HeLa cells. But Nagai et a ${ }^{56}$ claimed that the size of the CNTs is a factor for their cytotoxicity toward cells in suspended condition in culture media. However, the cytotoxicity of CNTs present in a scaffold is debatable. Giannona et $\mathrm{al}^{57}$ and a series of studies by Lobo et al ${ }^{58-61}$ revealed that the CNT films and scaffolds were biocompatible with cultured cells because they were not endocytosed by the cells. Results found in this laboratory are promising in that $\mathrm{COOH}-\mathrm{MWCNT}$ substrate provides an environment of low cytotoxicity. 


\section{In vitro differentiation study}

Cell differentiation should be the critical evaluation point for biomaterials because it directly contributes to tissue repair. Cells in their natural microenvironment interact with ECM components in the nanometer scale. ${ }^{62}$ Therefore, nanoscaled biomaterials show a positive effect on cellular functions and differentiation of stem cells. We hypothesized that changing the nanoscale topography of the cell culture substrate by using different functionalized CNTs might modulate in vitro differentiation of canine MSCs.

\section{Osteogenic differentiation}

We investigated the influence of carboxylated and pegylated CNTs on the osteogenic differentiation potential of canine
MSCs. Alizarin Red staining was done on control and CNT films after 21 days of osteogenic induction. Difference in mineralized aggregates was noticed on CNT substrates. The number and size of nodules were higher and the color was also darker in the treatment groups. Apparently, these differences were more prominent on the COOH-MWCNT group (Figure 6A). We also detected the relative expressions of three representative bone marker genes $O C N, O P N$, and Col IA1. The analysis revealed that the expression level of the target genes on the CNT films was significantly upregulated in most of the cases. OCN, the marker for matured osteoblasts, reflected a five- to sixfold overexpression in the COOH-SWCNT group and $>20$-fold increase on MWCNT substrate after 21 days when $O P N$ and Col IAI were also
A
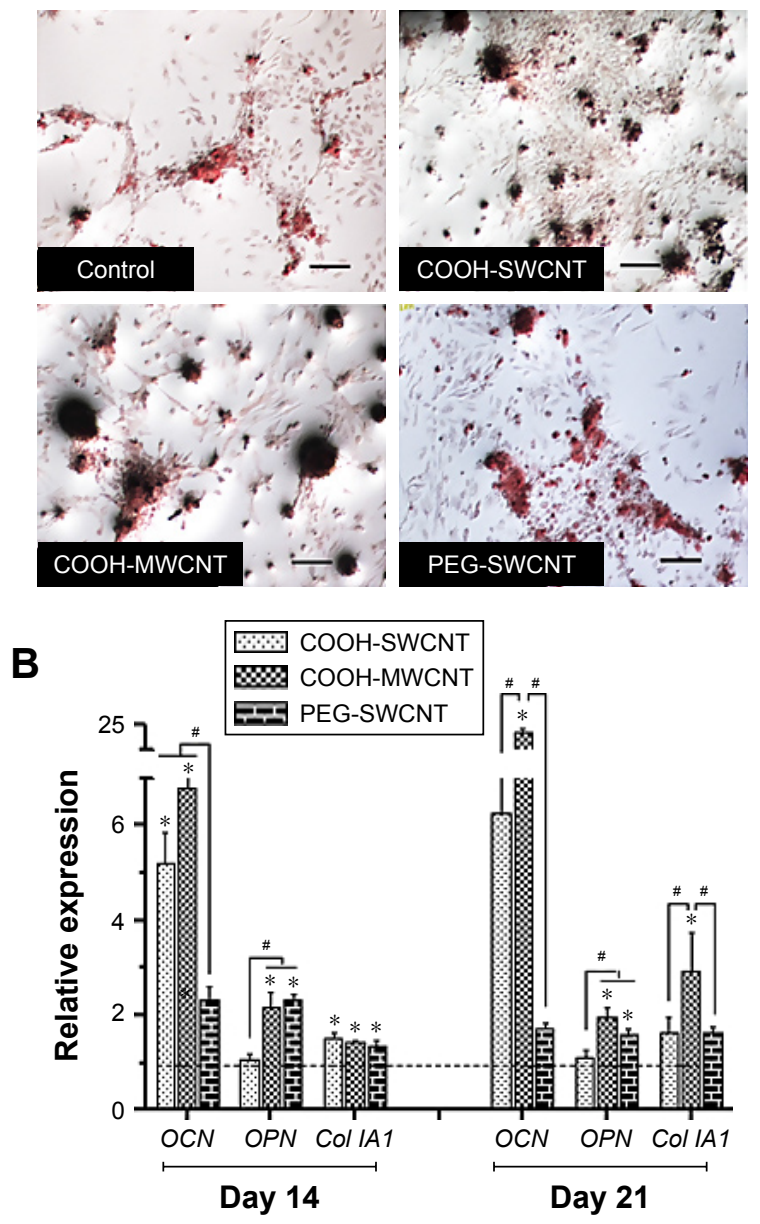

C
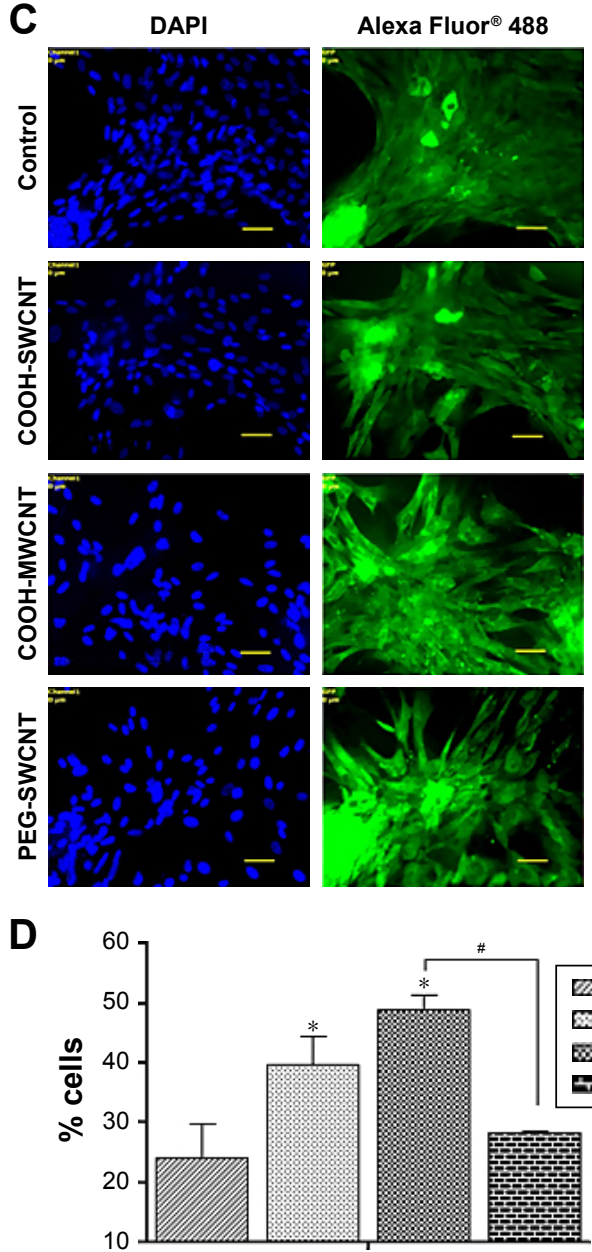
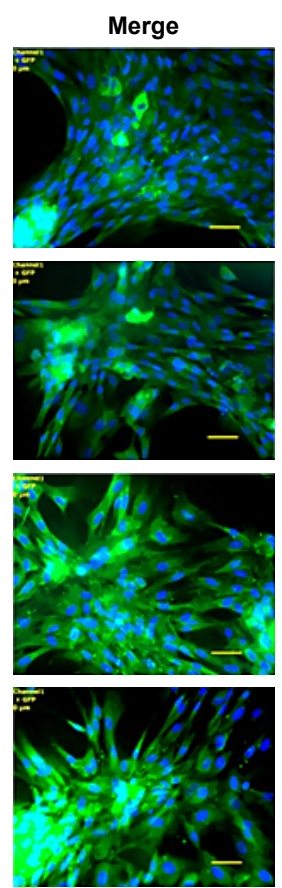

$\mathrm{COOH}-\mathrm{SWCNT}$

COOH-MWCNT PEG-SWCNT

Figure 6 Induced osteogenic differentiation of canine MSCs on CNT films.

Notes: (A) Representative images of Alizarin Red staining after 21 days of osteogenic differentiation in control and different CNT films. The size and darkness of mineralized nodules were higher on CNT substrates compared to control. Scale bars: $100 \mu \mathrm{m}$. (B) Relative expression of bone marker genes of canine MSCs differentiated on control and different CNT films. Results normalized to GAPDH relative to control. Dashed line indicates values of target genes in control conditions. The symbols * and \# indicate significance $(P<0.05)$ with respect to control and between the films, respectively, for a target gene. The results are the mean \pm standard error of the mean of the triplicate experiments. (C) Immunofluorescence of osteocalcin-positive cells (green), DAPI nuclear staining (blue), and merged fluorescence images on control and CNT films after $2 \mathrm{I}$ days. Scale bars: $50 \mu \mathrm{m}$. (D) Flow cytometry assay of osteocalcin-positive cells (percentage) after 2I days of osteogenic differentiation on control and different CNT films. The symbols * and \# indicate significance $(P<0.05)$ with respect to control and between the films, respectively. The results are the mean \pm standard error of the mean of the triplicate experiments.

Abbreviations: CNT, carbon nanotube; DAPI, 4',6-diamidino-2-phenylindole; GAPDH, glyceraldehyde 3-phosphate dehydrogenase; MSC, mesenchymal stem cell; MWCNT, multiwalled CNT; PEG, polyethylene glycol; SWCNT, single-walled CNT. 
found to be better expressed (Figure 6B). Since $O C N$ was highly expressed after 21 days of differentiation, we immunostained these cells with anti-osteocalcin antibody for both control and CNT substrates to confirm the differentiation. Cells were positive for osteocalcin in the control and all the types of CNT films (Figure 6C). Flow cytometry was done to quantify the percentage of osteocalcin-positive cells and we could find a significantly higher population of positive cells on the $\mathrm{COOH}$-functionalized CNT films (Figure 6D). The relative expression of osteogenic genes as well as flow cytometry findings indicated that the osteogenic differentiation on PEG-SWCNT films was moderately lower compared to COOH-functionalized CNT substrates.

The major phases occurring in osteogenesis have been well established ${ }^{63}$ and display a sequentially organized expression pattern of typical markers. $O C N$ and $O P N$ are the differentiated osteoblast-specific genes for mineralization of the bone matrix. ${ }^{64,65}$ These two genes were found to be overexpressed on the CNT substrates in our study period. Specifically, highly significant expression of $O C N$ in $\mathrm{COOH}$-functionalized CNT substrates indicated more mature osteoblastic cells. Greater number and size of mineralized nodules in Alizarin Red staining and higher percentage of osteocalcin-positive cells on the films in FACS are also in accordance with our gene expression study after 21 days. But we also noticed differences in $\operatorname{Col} 1 A$ expression during this osteogenic differentiation process. It is speculated that the presence of CNT, which mimics collagen fibrils, leads to a production of collagen, but this phenomenon is not desirable in osteogenic differentiation.

A possible explanation of the enhanced osteogenesis might be the stress on cells due to the topographical manipulation of the culture substrate by the CNT layer, leading to enhanced cell spreading and tensile strength of the actin filament. ${ }^{66-68}$ Furthermore, it has been shown that the roughness of the underlying substrate influences spatial distribution and cell differentiation. ${ }^{15,69,70}$ Improved osteogenesis of MSCs from different sources is well established in most of the studies reported, ${ }^{11,12,14,15,71}$ but in one study, ${ }^{50}$ osteogenic differentiation of mice bone marrow MSCs was reduced on MWCNT substrate. In our experiment, by overall observation, we theorized that $\mathrm{COOH}-\mathrm{MWCNT}$ substrate acted as a better cue, accelerating the osteogenic differentiation process of canine MSCs.

\section{Chondrogenic differentiation}

The capacity of canine MSCs to undergo chondrogenesis was assessed on control and CNT substrates. Chondrogenic differentiation was confirmed by Alcian Blue staining showing the accumulation of glycosaminoglycans (GAGs) on all the substrates. Although we have not quantified it, grossly no difference was noticed in staining between the control and treatment groups (Figure 7A). Time-dependent relative gene expression analysis of chondrogenic differentiation was performed using RT-PCR (Figure 7B). The expression of $A C A N$ and $C o l 2 A 1$, integral cartilage ECM components, was transient, reaching peak expression at Day 14 and decreasing thereafter in all the treatment groups. However, it is important to note that both these genes were found to be significantly upregulated on $\mathrm{COOH}-\mathrm{SWCNT}$ substrate up to the end of the experiment, whereas in MWCNT, only $A C A N$ was found to be significantly upregulated but the expression level was moderately low in comparison to the $\mathrm{COOH}-$ SWCNT substrate throughout the study. An initial higher expression of $\mathrm{SOX} 9$ was noticed on $\mathrm{COOH}-\mathrm{SWCNT}$ films. After 21 days of culture, immunostaining with anti-aggrecan antibody confirmed the chondrogenic differentiation on both control and CNT films (Figure 7C). Flow cytometry assay for the quantification of aggrecan-positive cells revealed a significant increase on $\mathrm{COOH}-\mathrm{SWCNT}$ substrate. But, in the PEG-SWCNT film, a significantly less number of cells had been differentiated (Figure 7D).

Increased expression of $A C A N$ and $\operatorname{Col} 2 A 1$, two major chondrocyte-specific genes, on CNT films at the initial stage of the experiment, ie, Day 14, suggests that modification of surface topography by CNTs might have promoted ECM expression in the culture system. In an experiment, Chahine et $\mathrm{al}^{72}$ found that the surface coating of SWCNT regulates the biological response of chondrocytes and the charged nature of the $\mathrm{COOH}$ group increases $\mathrm{Col} 2 \mathrm{Al}$ expression. Scaffolds with SWCNT-based nanomaterial have greatly enhanced GAG synthesis and chondrogenic differentiation of hMSCs within 2 weeks. ${ }^{17}$ Applications of different biomaterials in chondrocyte tissue engineering show that soft fiber condition generally promotes greater degree of chondrogenesis and RGD (arginylglycylaspartic acid) density, an element for cellular recognition which is a critical regulator of this lineage commitment. ${ }^{73} \mathrm{CNT}$-coated coverslip is a rigid structure with lack of softness, which might have caused the decrease in gene expression during the latter half of the study. Mooney et $\mathrm{al}^{13}$ found a slight decrease of chondrogenesis of hMSCs when cultured in a CNT-suspended media. However, in our study, $\mathrm{COOH}-$ SWCNT enhanced chondrogenesis in a better way compared to other CNT substrates in terms of gene expression and aggrecan-positive cells. 
A
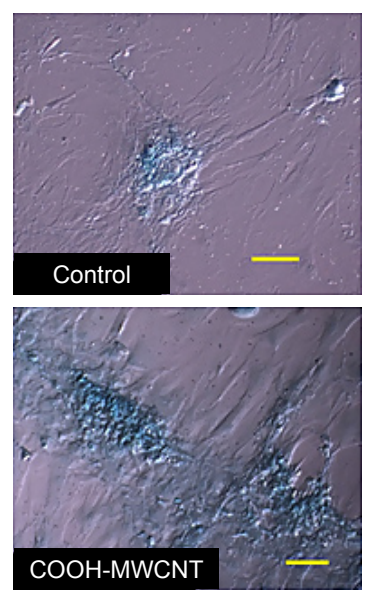
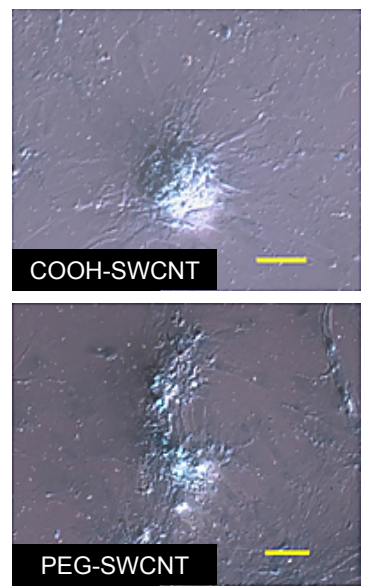

B

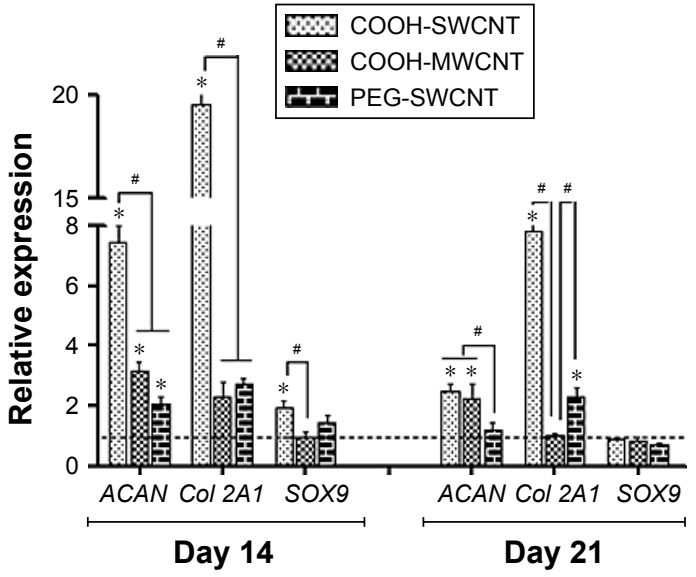

C
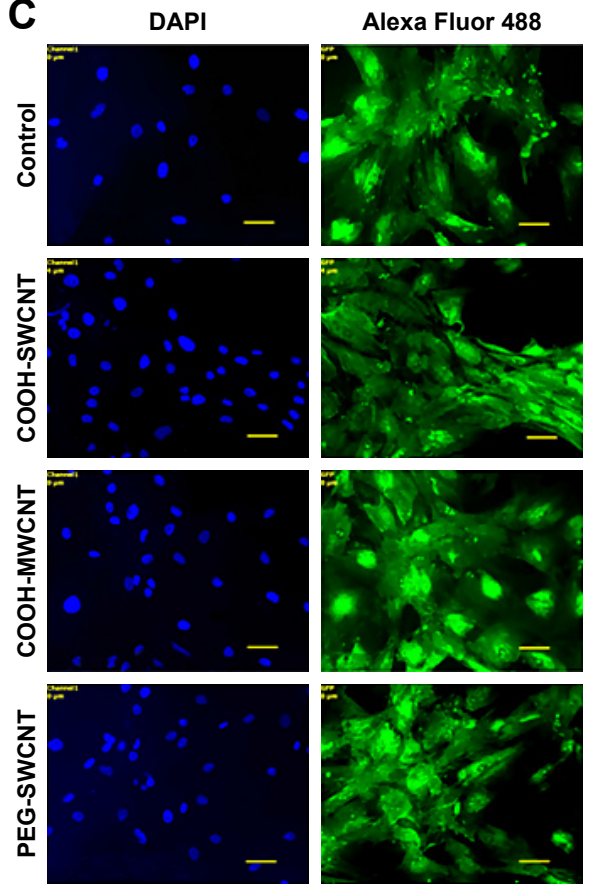

D

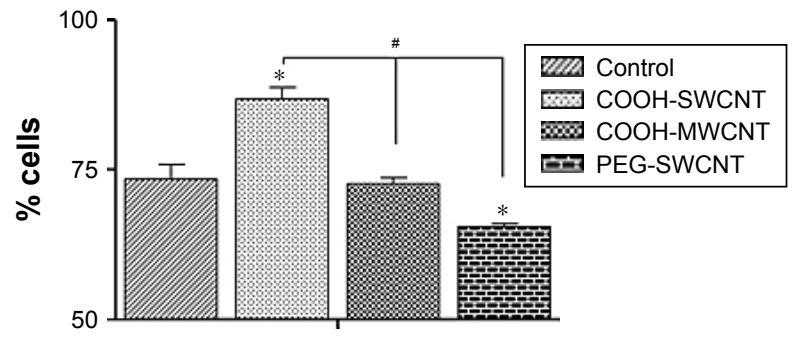

Figure 7 Induced chondrogenic differentiation of canine MSCs on CNT films.

Notes: (A) Representative images of Alcian Blue staining after 21 days of chondrogenic differentiation on control and different CNT films. Scale bar: I00 $\mu$ m. (B) Relative expression of chondrogenesis marker genes of canine MSCs differentiated on control and different CNT films. Results normalized to GAPDH relative to control. Dashed line indicates values of target genes in control conditions. The symbols * and * indicate significance $(P<0.05)$ with respect to control and between the films, respectively, for a target gene. The results are the mean \pm standard error of the mean of the triplicate experiments. (C) Immunofluorescence of aggrecan-positive cells (green), DAPI nuclear staining (blue), and merged fluorescence images on control and CNT films after 21 days. Scale bars: $50 \mu \mathrm{m}$. (D) Flow cytometry assay of aggrecan-positive cells (percentage) after $2 \mathrm{I}$ days of chondrogenic differentiation on control and different CNT films. The symbols * and \# indicate significance $(P<0.05)$ with respect to control and between the films, respectively. The results are the mean \pm standard error of the mean of the triplicate experiments.

Abbreviations: CNT, carbon nanotube; DAPI, 4',6-diamidino-2-phenylindole; GAPDH, glyceraldehyde 3-phosphate dehydrogenase; MSC, mesenchymal stem cell; MWCNT, multiwalled CNT; PEG, polyethylene glycol; SWCNT, single-walled CNT.

\section{Neuronal differentiation}

BME-induced neuronal differentiation process of canine MSCs caused rapid changes in their appearance, from fibroblastic to a more elongated morphology after 24 hours of preinduction (Figure 8A) and, subsequently, neuronlike characteristics with multiple branching in some cells after 6 days of induction (Figure 8B). Cells became less adherent to the culture flask, and there was a considerable reduction of the cell number during this differentiation process. Relative expressions of neuron-specific gene markers were evaluated after 7 days (including 24-hour preinduction) on both the control and CNT films. Expressions of $T U B B 3$ and NCAM were significantly increased on the $\mathrm{COOH}$-functionalized substrates. Moreover, MAP2 was also upregulated but the change was noticed to be significant only in the $\mathrm{COOH}-\mathrm{SWCNT}$ group. Nestin (NES) expression on the $\mathrm{COOH}$-functionalized substrates was found to be decreased compared to control, whereas it was significantly higher on PEG-SWCNT film (Figure 8C). The cells were positive for immunophenotypic expression of $\beta$-III tubulin and MAP2 on control and CNT substrates, confirming the differentiation (Figure 9A and B). Flow cytometry was done to quantify the percentage of $\beta$-III tubulin-positive cells, and a higher number of positive cells was found on the $\mathrm{COOH}$ functionalized substrates (Figure 9C). At higher magnification, in immunofluorescence studies of both $\beta$-III tubulin and MAP2, more neurite-like branching was visible on the CNT films compared to control (Figure 10). 
A
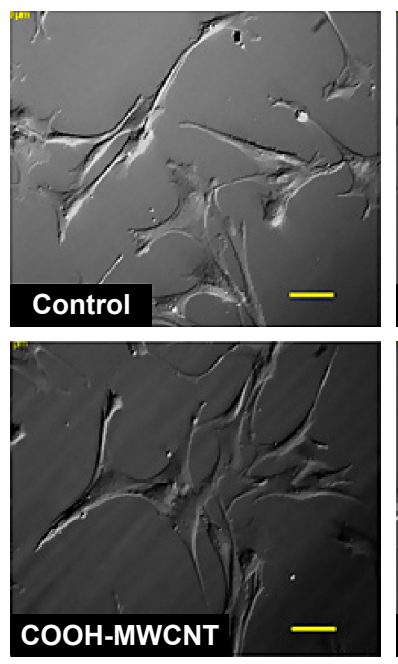
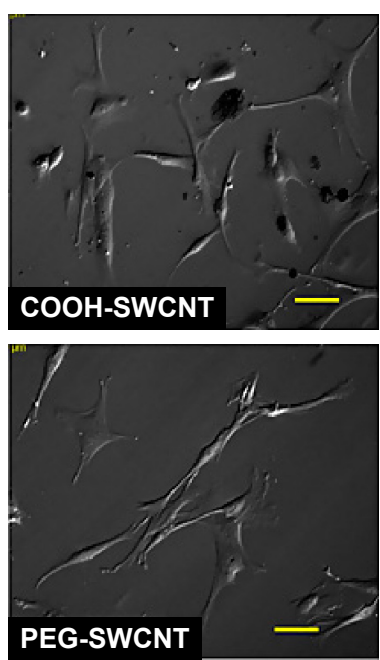

B
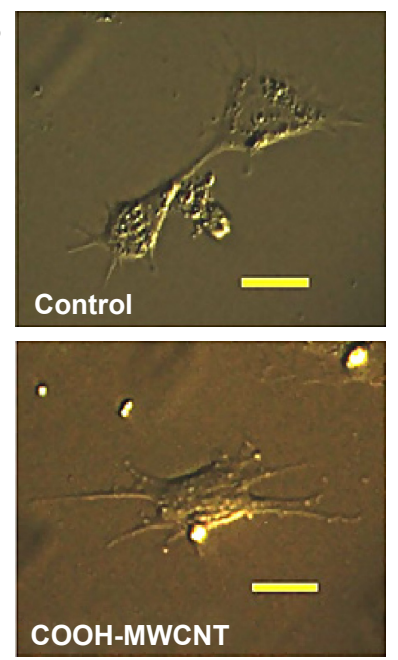
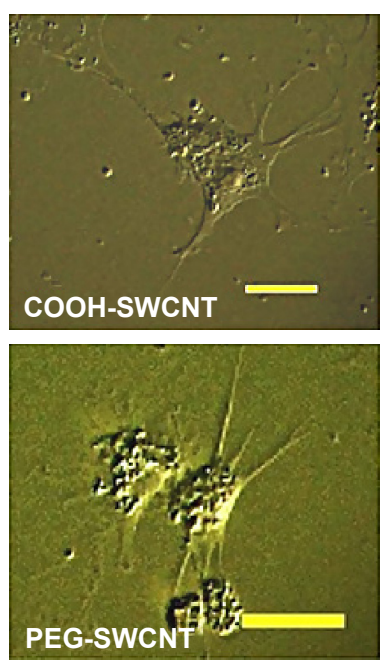

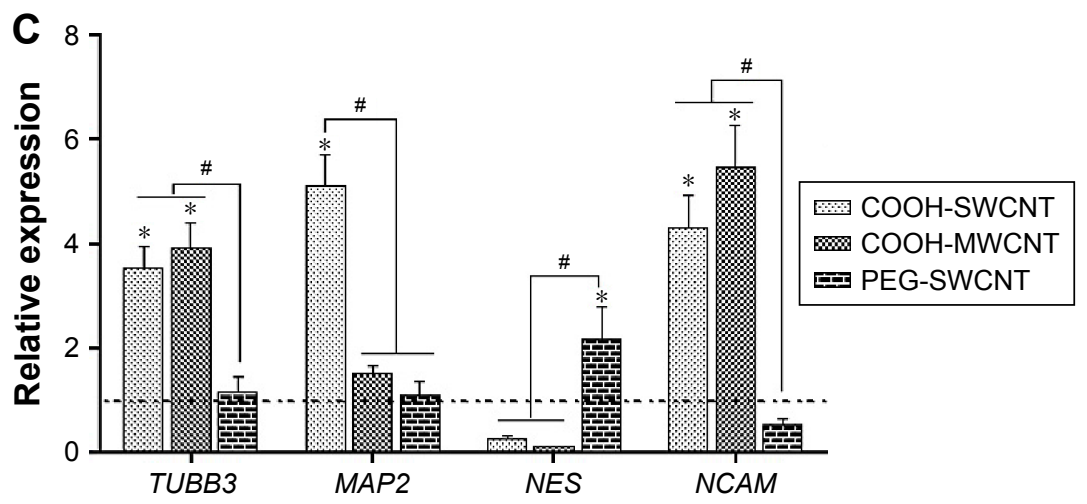

Figure 8 Induced neuronal differentiation of canine MSCs on CNT films.

Notes: (A) Morphological changes after 24 hours of preinduction. Scale bars: $50 \mu \mathrm{m}$. (B) Morphological changes after 6-day induction for neuronal differentiation on the control and different CNT films. Scale bars: $20 \mu \mathrm{m}$. (C) Relative expression of neuronal marker genes of canine MSCs differentiated on control and different CNT films. Results normalized to GAPDH relative to control. Dashed line indicates values of target genes in control conditions. The symbols * and ${ }^{\#}$ indicate significance $(P<0.05)$ with respect to control and between the films, respectively, for a target gene. The results are the mean \pm standard error of the mean of the triplicate experiments.

Abbreviations: CNT, carbon nanotube; GAPDH, glyceraldehyde 3-phosphate dehydrogenase; MSC, mesenchymal stem cell; MWCNT, multiwalled CNT; PEG, polyethylene glycol; SWCNT, single-walled CNT.

Neuronal differentiation of MSCs isolated from humans, rats, and mice has been reported by several investigators. ${ }^{44,74,75}$ Canine MSCs naturally express some of the neural markers ${ }^{76}$ and show neuronal differentiation potentiality when isolated from various sources such as adipose tissue, ${ }^{77}$ amniotic fluid, ${ }^{78}$ and bone marrow. ${ }^{79}$ CNTs have been studied as culture substrates to support neuron growth and differentiation basically due to their electrical conductivity as well as their nanotopographical feature creating tight contacts with neuron membranes, leading to electrical shortcuts. ${ }^{80,81}$ It has also been noticed that human and rat bone marrow-derived MSCs can spontaneously differentiate into neuronal lineage on CNT substrates. ${ }^{16,82}$

$\beta$-III Tubulin, a major component of microtubules, is exclusively found in neural cells; MAP2 is a mature neuron marker believed to be essential for the formation of neurites, and NCAM is expressed on most neuroectodermal-derived cell lines and tissues. ${ }^{77,83,84}$ Herein, neuronal induction of the cells showed neuron-like morphology, with multiple neurite-like branches, and cells were immunopositive for $\beta$-III tubulin and MAP2, indicating that the canine MSCs had differentiated into mature neurons both in control and on the CNT substrates. The expression profiles of these three genes (TUBB3, MAP2, and NCAM) indicated an enhanced differentiation of canine MSCs into mature neurons on the $\mathrm{COOH}$-functionalized CNT films. Flow cytometry findings of higher percentage of $\beta$-III tubulin-positive cells on $\mathrm{COOH}$-functionalized CNT films were in accordance with the gene expression study. Nestin (NES) is an intermediate filament protein, considered as a transient neurogenic marker of neuronal precursor stem cells. ${ }^{85} \mathrm{It}$ is well established that expression of NES decreases with neuronal maturation, which was also evident in canine MSCs while differentiating into neurons. ${ }^{77,86}$ In the current experiment, NES expression 
A
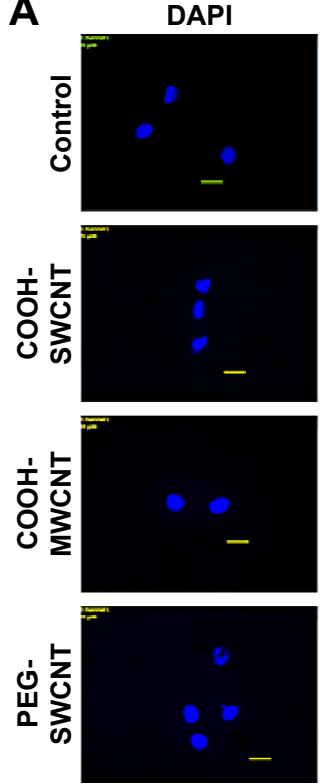

Alexa Fluor 488
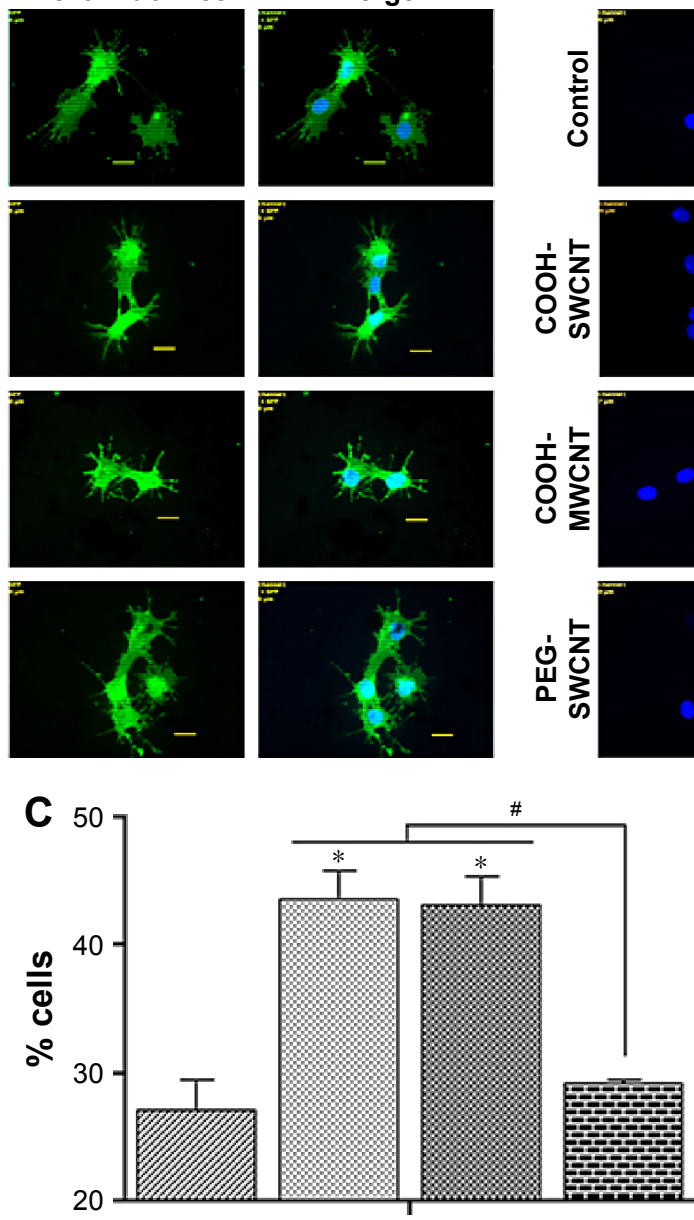

B
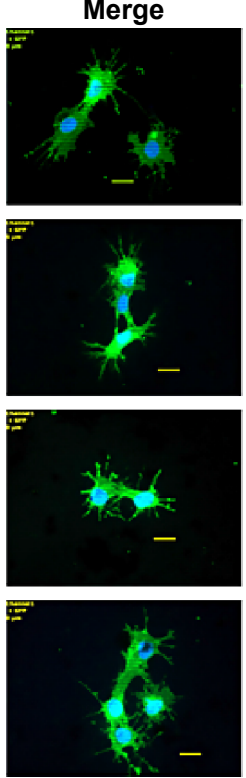

Alexa Fluor 594
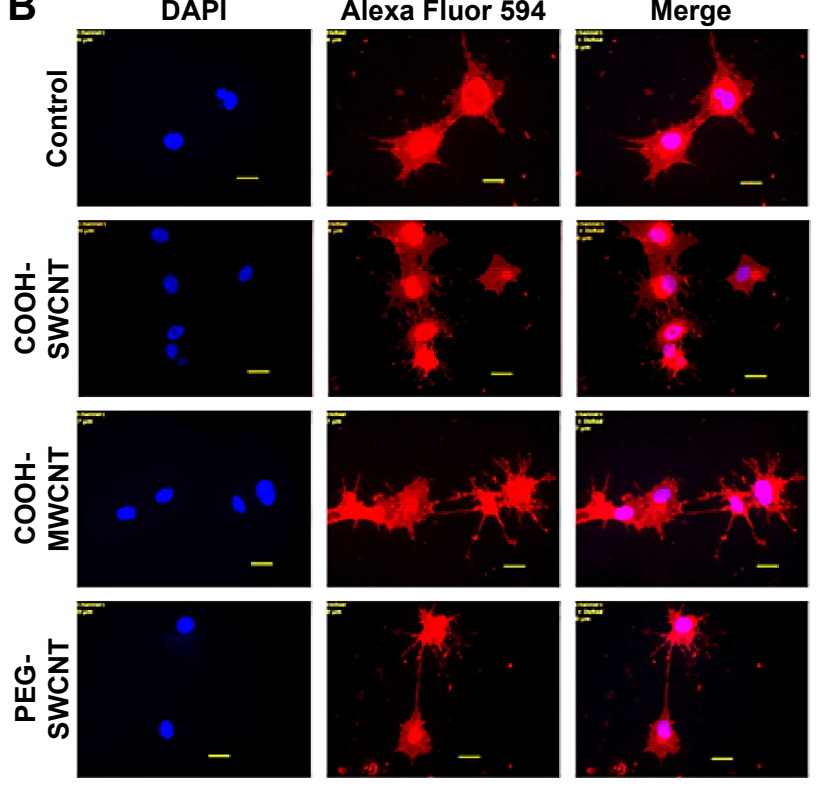

Control
COOH-SWCNT
COOH-MWCNT
PEG-SWCNT

Figure 9 Immunofluorescence and flow cytometry results of canine MSCs after neuronal differentiation on control and CNT films after 7 days.

Notes: Immunofluorescence of (A) $\beta$-III tubulin-positive cells (green) and (B) MAP2-positive cells (red), DAPI nuclear staining (blue), and merged fluorescence images. Scale bars: $20 \mu \mathrm{m}$. (C) Flow cytometry assay of $\beta$-III tubulin-positive cells (percentage). The symbols * and ${ }^{*}$ indicate significance $(P<0.05)$ with respect to control and between the films, respectively. The results are the mean \pm standard error of the mean of the triplicate experiments.

Abbreviations: GAPDH, glyceraldehyde 3-phosphate dehydrogenase; MSC, mesenchymal stem cell; DAPI, 4',6-diamidino-2-phenylindole; CNT, carbon nanotube; MWCNT, multiwalled CNT; PEG, polyethylene glycol; SWCNT, single-walled CNT.

decreased on both the COOH-functionalized CNT films, indicating that cells have differentiated into more mature neurons. Interaction of neuron and its microenvironment, as well as the conductivity of CNTs, makes the culture substrate more preferable for neurite branching. ${ }^{87}$ We have also observed a better neurite branching of the differentiated cells on the CNT substrates. The overall neuronal differentiation results of this study indicate that the $\mathrm{COOH}$-functionalized CNT topography might be the dominating factor for better neuronal differentiation of canine MSCs.


Figure 10 Morphological differences in (A) $\beta$-III tubulin-positive cells and (B) MAP2-positive cells by immunofluorescence on control and CNT films at higher magnification. Notes: Scale bars: $2 \mu \mathrm{m}$. More neurite-like branches are visible on the CNT films compared to control.

Abbreviations: CNT, carbon nanotube; DAPI, 4',6-diamidino-2-phenylindole. 


\section{Conclusion}

Nanostructures with suitable chemical and biological cues could serve as a platform to support the proliferation and differentiation of MSCs. In this study, we evaluated the effect of three different varieties of CNT films on canine bone marrow-derived MSCs as an in vitro cellular model. CNT films induced some morphological changes along with slower proliferation rate of the cells. COOH-MWCNT substrate was found to be more cytocompatible with respect to proliferation and apoptosis studies. This study also illustrated that, by subjecting canine MSCs to appropriately selected functionalized CNTs, it is possible to propel the targeted differentiation. The results suggest that $\mathrm{COOH}-$ MWCNT and COOH-SWCNT acted as better cues for osteogenic and chondrogenic differentiation, respectively, while both promoted neuronal differentiation. To our knowledge, this study is the first to report the collective cellular behavior and multiple lineage-specific differentiation of canine bone marrow-derived MSCs on the thin film scaffolds of CNTs; moreover, emphasis has also been given to the cytocompatibility of these fabricated culture substrates. The findings of this study, together with ongoing research on other species, will lead to better understanding of MSC behavior and differentiation, which is crucial for the development of functional tissue on CNT-based scaffolds; furthermore, canine MSCs may be used as a future experimental model in stem cell-based regenerative medicine.

\section{Acknowledgments}

The authors thankfully acknowledge the Director, Indian Council of Agricultural Research - Indian Veterinary Research Institute, Izatnagar, Uttar Pradesh, India, for the research grant to conduct this study. We thank Sanjhali Soren for the assistance in preparation of the manuscript.

\section{Disclosure}

The authors report no conflicts of interest in this work.

\section{References}

1. Jiang Y, Jahagirdar BN, Reinhardt RL, et al. Pluripotency of mesenchymal stem cells derived from adult marrow. Nature. 2002;418(6893): $41-49$.

2. Gronthos S, Franklin DM, Leddy HA, Robey PG, Storms RW, Gimble JM. Surface protein characterization of human adipose tissuederived stromal cells. J Cell Physiol. 2001;189(1):54-63.

3. Erices A, Conget $P$, Minguell JJ. Mesenchymal progenitor cells in human umbilical cord blood. Br J Haematol. 2000;109(1):235-242.

4. Fuchs E, Tumbar T, Guasch G. Socializing with the neighbours: stem cells and their niche. Cell. 2004;116(6):769-778.

5. Dalby MJ, Gadegaard N, Tare R, et al. The control of human mesenchymal cell differentiation using nanoscale symmetry and disorder. Nat Mater. 2007;6(12):997-1003.
6. Oh S, Karla S, Brammer YS, et al. Stem cell fate dictated solely by altered nanotube dimension. Proc Natl Acad Sci U S A. 2009;106(7): 2130-2135.

7. Thorstenson ET, Ren Z, Chou TW. Advances in science and technology of carbon nanotubes and their composites: a review. Compos $S c i$ Technol. 2001;61:1899.

8. Saito R, Kataura H. Optical properties and Raman spectroscopy of carbon nanotubes. In: Dresselhus MS, Dresselhaus G, Avouris P, editors. Carbon Nanotubes: Synthesis, Structure, Properties and Applications. Berlin: Springer; 2001:213-247.

9. Ouyang M, Huang JL, Lieber C. Fundamental electronic properties and applications of single walled carbon nanotubes. Acc Chem Res. 2002;35(12):1018-1025.

10. Troiani HE, Miki YM, Camacho-Bragado GA, et al. Direct observation of the mechanical properties of single walled carbon nanotubes and their junctions at the atomic level. Nano Lett. 2003;3:751.

11. Tay CY, Gu HG, Leong WS, et al. Cellular behaviour of human mesenchymal stem cells cultured on single-walled carbon nanotube film. Carbon N Y. 2010;48:1095-1104.

12. Nayak TR, Jian L, Phua LC, Ho HK, Ren Y, Pastorin G. Thin films of functionalized multiwalled carbon nanotubes as suitable scaffold materials for stem cells proliferation and bone formation. ACS Nano. 2010;4(12):7717-7725.

13. Mooney E, Dockery P, Greiser U, et al. Carbon nanotubes and mesenchymal stem cells: biocompatibility, proliferation and differentiation. Nano Lett. 2008;8(8):2137-2143.

14. Baik KY, Park SY, Heo K, et al. Carbon nanotube monolayer cues for osteogenesis of mesenchymal stem cells. Small. 2011;7(6):741-745.

15. LiX, Liu H, Niu X, et al. The use of carbon nanotubes to induce osteogenic differentiation of human adipose-derived MSCs in vitro and ectopic bone formation in vivo. Biometerials. 2012;33(19):4818-4827.

16. Chen YS, Hsiue GH. Directing neural differentiation of mesenchymal stem cells by carboxylated multiwalled carbon nanotubes. Biomaterials. 2013;34(21):4936-4944.

17. Holmes B, Fang X, Zarate A, et al. Enhanced human bone marrow mesenchymal stem cell chondrogenic differentiation in electrospun constructs with carbon nanomaterials. Carbon N Y. 2016;97:1-13.

18. Kitahari H, Kuboki Y, Takita H, et al. Culture of ES cells and mesenchymal stem cells on carbon nanotube scaffolds. Nano Biomed. 2010;2:81-92.

19. Lee JH, Shim W, Khalid NC, et al. Random network of single-walled carbon nanotubes promotes mesenchymal stem cell's proliferation and differentiation. ACS Appl Mater Interfaces. 2015;7(3):1560-1567.

20. Chao TI, Xiang S, Chen CS, et al. Carbon nanotubes promote neuron differentiation from human embryonic stem cells. Biochem Biophys Res Commun. 2009;384(4):426-430.

21. Chao TI, Xiang S, Lipstate JF, et al. Poly(methacrylic acid)-grafted carbon nanotube scaffolds enhance differentiation of hESCs into neuronal cells. Adv Mater. 2010;22(32):3542-3547.

22. Sridharan I, Kim T, Wang R. Adapting collagen/CNT matrix in directing hESC differentiation. Biochem Biophys Res Commun. 2009; 381(4):508-512.

23. Harrison BS, Atala A. Carbon nanotube applications for tissue engineering. Biomaterials. 2007;28(2):344-353.

24. Saito N, Usui Y, Aoki K, et al. Carbon nanotubes: biomedical applications. Chem Soc Rev. 2009;38:1897-1903.

25. Tsai KL, Clark LA, Murphy KE. Understanding hereditary diseases using the dog and human as companion model systems. Mamm Genome. 2007;18(6-7):444-451.

26. Chiou WL, Jeong HY, Chung SM, Wu TC. Evaluation of using dog as an animal model to study the fraction of oral dose absorbed of 43 drugs in humans. Pharm Res. 2000;17(2):135-140.

27. Schneider MR, WolfE, Braun J, Kolb HJ, Adler H. Canine embryo-derived stem cells and models for human diseases. Hum Mol Genet. 2008;17(R1): R42-R47.

28. Vieira NM, Brandalise V, Zucconi E, Secco M, Strauss BE, Zatz M. Isolation, characterization and differentiation potential of canine adiposederived stem cells. Cell Transplant. 2010;19(3):279-289. 
29. Lee KS, Nah JJ, Lee BC, et al. Maintenance and characterization of multipotent mesenchymal stem cells isolated from canine umbilical cord matrix by collagenase digestion. Res Vet Sci. 2013;94(1):144-151.

30. Seo MS, Jeong YH, Park JR, et al. Isolation and characterization of canine umbilical cord blood-derived mesenchymal stem cells. J Vet Sci. 2009;10(3):181-187.

31. Zucconi E, Vieira NM, Bueno DF, et al. Mesenchymal stem cells derived from canine umbilical cord vein - a novel source for cell therapy studies. Stem Cells Dev. 2010;19(3):395-402.

32. Filioli Uranio M, Valentini L, Lange-consiglio A, et al. Isolation, proliferation, cytogenetic, and molecular characterization and in vitro differentiation potency of canine stem cells from foetal adnexa: a comparative study of amniotic fluid, amnion, and umbilical cord matrix. Mol Reprod Dev. 2011;78:361-373.

33. Kisiel AH, McDuffee LA, Masaoud E, Bailey TR, Esparza Gonzalez $\mathrm{BP}$, Nino-Fong R. Isolation, characterization, and in vitro proliferation of canine mesenchymal stem cells derived from bone marrow, adipose tissue, muscle, and periosteum. Am J Vet Res. 2012;73(8):1305-1317.

34. DeBakker E, Van Ryssen B, De Schauwer C, Meyer E. Canine mesenchymal stem cells: state of the art, perspectives as therapy for dogs and as a model for man. Vet Q. 2013;33(4):225-233.

35. Mostafa AA, Zaazou MH, Chow LC, et al. Injectable nanoamorphous calcium phosphate based in situ gel systems for the treatment of periapical lesions. Biomed Mater. 2015;10(6):065006.

36. Du B, Liu W, Deng Y, et al. Angiogenesis and bone regeneration of porous nano-hydroxyapatite/coralline blocks coated with rhVEGF165 in critical-size alveolar bone defects in vivo. Int $J$ Nanomedicine. 2015;10:2555-2565.

37. Zeng $\mathrm{Y}$, Chen $\mathrm{C}$, Liu $\mathrm{W}$, et al. Injectable microcryogels reinforced alginate encapsulation of mesenchymal stromal cells for leak-proof delivery and alleviation of canine disc degeneration. Biomaterials. 2015; 59:53-65.

38. Zang S, Dong G, Peng B, et al. A comparison of physicochemical properties of sterilized chitosan hydrogel and its applicability in a canine model of periodontal regeneration. Carbohydr Polym. 2014; 113:240-248.

39. Chen YS, Tsou PC, Lo JM, Tsai HC, Wang YZ, Hsiue GH. Poly(N-isopropylacrylamide) hydrogels with interpenetrating multiwalled carbon nanotubes for cell sheet engineering. Biomaterials. 2013;34(30):7328-7334.

40. Matta-Domjan B, Alice K, Mazhar A, et al. Carbon nanotubes: a promising tissue engineering approach for in vitro cultivation \& differentiation of primary canine articular chondrocytes. BMC Musculoskelet Disord. 2015;16:S20.

41. Paul A, Shao W, Shum-Tim D, Prakash S. The attenuation of restenosis following arterial gene transfer using carbon nanotube coated stent incorporating TAT/DNA (Ang1+Vegf) nanoparticles. Biomaterials. 2012;33(30):7655-7664

42. Barrientos-Durán A, Carpenter EM, Zur Nieden NI, Malinin TI, Rodríguez-Manzaneque JC, Zanello LP. Carboxyl-modified single-wall carbon nanotubes improve bone tissue formation in vitro and repair in an in vivo rat model. Int J Nanomedicine. 2014;9:4277-4291.

43. Pfaffl MW. A new mathematical model for relative quantification in real-time RT-PCR. Nucleic Acid Res. 2001;29(9):e45

44. Woodbury D, Schwarz EJ, Prockop DJ, Black IB. Adult rat and human bone marrow stromal cells differentiate into neurons. J Neurosci Res. 2000;61(4):364-370

45. Mejillano MR, Kojima S, Applewhite DA, Gertler FB, Svitkina TM, Borisy GG. Lamellipodial versus filopodial mode of the actin nanomachinery: pivotal role of the filament barbed end. Cell. 2004;118(3): 363-373.

46. Deligianni DD. Multiwalled carbon nanotubes enhance human bone marrow mesenchymal stem cells' spreading but delay their proliferation in the direction of differentiation acceleration. Cell Adh Migr. 2014;8(6):558-562.

47. Zhao C, Tan A, Pastorin G, Ho HK. Nanomaterial scaffolds for stem cell proliferation and differentiation in tissue engineering. Biotechnol Adv. 2013;31(5):654-668.
48. Fletcher DA, Mullins RD. Cell mechanics and the cytoskeleton. Nature. 2010;463(7280):485-492.

49. Storm C, Pastore JJ, MacKintosh FC, Lubensky TC, Janmey PA. Nonlinear elasticity in biological gels. Nature. 2005;435(7039):191-194.

50. Liu D, Yi C, Zhang D, Zhang J, Yang M. Inhibition of proliferation and differentiation of mesenchymal stem cells by carboxylated carbon nanotubes. ACS Nano. 2010;4(4):2185-2195.

51. Namgung S, Baik KY, Park J, Hong S. Controlling the growth and differentiation of human mesenchymal stem cells by the arrangement of individual carbon nanotubes. ACS Nano. 2011;5(9):7383-7390.

52. Yim EK, Pang SW, Leong KW. Synthetic nanostructures inducing differentiation of human mesenchymal stem cells into neuronal lineage. Exp Cell Res. 2007;313(9):1820-1829.

53. McIlwain DR, Berger T, Mak TW. Caspase functions in cell death and disease. Cold Spring Harb Perspect Biol. 2013;5(4):a008656.

54. Lacerda L, Bianco A, Prato M, Kostarelos K. Carbon nanotubes as nanomedicines: from toxicology to pharmacology. Adv Drug Deliv Rev. 2006;58(14):1460-1470.

55. Chin SF, Baughman RH, Dalton AB, et al. Amphiphilic helical peptide enhances the uptake of single-walled carbon nanotubes by living cells. Exp Biol Med. 2007;232(9):1236-1244.

56. Nagai H, Okazaki Y, Chew $\mathrm{SH}$, et al. Diameter and rigidity of multiwalled carbon nanotubes are critical factors in mesothelial injury and carcinogenesis. Proc Natl Acad Sci US A. 2011;108(49):E1330-E1338.

57. Giannona S, Firkowska I, Rojas-Chapana J, Giersig M. Vertically aligned carbon nanotubes as cytocompatible material for enhanced adhesion and proliferation of osteoblast-like cells. J Nanosci Nanotechnol. 2007;7(4-5):1679-1683.

58. Lobo AO, Cora MAF, Antunes EF, et al. An evaluation of cell proliferation and adhesion on vertically-aligned multiwalled carbon nanotube films. Carbon N Y. 2010;48:245-254.

59. Lobo AO, Antunes EF, Machado AHA, et al. Cell viability and adhesion on as grown multi-wall carbon nanotube films. Mater Sci Eng C. 2008;28:264-269.

60. Lobo AO, Antunes EF, Palma MBS, et al. Biocompatibility of multiwalled carbon nanotubes grown on titanium and silicon surfaces. Mater Sci Eng C. 2008;28:532-538.

61. Lobo AO, Marciano FR, Ramos SC, et al. Increasing mouse embryonic fibroblast cells adhesion on superhydrophilic vertically aligned carbon nanotube films. Mater Sci Eng C. 2011;31:1505-1511.

62. Abrams GA, Goodman SL, Nealey PF, et al. Nanoscale topography of the basement membrane underlying the corneal epithelium of the rhesus macaque. Cell Tissue Res. 2000;299(1):39-46.

63. Zur Nieden NI, Kempka G, Ahr HJ. In vitro differentiation of embryonic stem cells into mineralized osteoblasts. Differentiation. 2003; 71(1):18-27.

64. McKee MD, Nanci A. Osteopontin: an interfacial extracellular matrix protein in mineralized tissues. Connect Tissue Res. 1996;35(1-4): 197-205.

65. Komori T, Yagi HS, Nomura A, et al. Targeted disruption of Cbfa1 results in a complete lack of bone formation owing to maturational arrest of osteoblasts. Cell. 1997;89(5):755-764.

66. McBeath R, Pirone DM, Nelson CM, Bhadriraju K, Chen CS. Cell shape, cytoskeletal tension, and RhoA regulate stem cell lineage commitment. Dev Cell. 2004;6(4):483-495.

67. Settleman J. Tension precedes commitment-even for a stem cell. Mol Cell. 2004;14(2):148-150.

68. Kilian KA, Bugarija B, Lahn BT, Mrksich M. Geometric cues for directing the differentiation of mesenchymal stem cells. Proc Natl Acad Sci US A. 2010;107(11):4872-4877.

69. Gomi K, Davies JE. Guided bone tissue elaboration by osteogenic cells in vitro. J Biomed Mater Res. 1993;27(4):429-431.

70. Curtis AS, Wilkinson CD. Reactions of cells to topography. J Biomater Sci Polym Ed. 1998;9(12):1313-1329.

71. Baktur R, Yoon SH, Kwon S. Effects of multiwalled carbon nanotube reinforced collagen scaffolds on the osteogenic differentiation of mesenchymal stem cells. J Nanomater. 2013;8. Article ID 904083. 
72. Chahine NO, Collette NM, Thomas CB, Genetos DC, Loots GG. Nanocomposite scaffold for chondrocyte growth and cartilage tissue engineering: effects of carbon nanotube surface functionalization. Tissue Eng Part A. 2014;20(17-18):2305-2315.

73. Kim IL, Khetan S, Baker BM, Chen CS, Burdick JA. Fibrous hyaluronic acid hydrogels that direct MSC chondrogenesis through mechanical and adhesive cues. Biomaterials. 2013;34(22):5571-5580.

74. Sanchez-Ramos J, Song S, Cardozo-Pelaez F, et al. Adult bone marrow stromal cells differentiate into neural cells in vitro. Exp Neurol. 2000; 164(2):247-256.

75. Deng J, Petersen BE, Steindler DA, Jorgensen ML, Laywell ED. Mesenchymal stem cells spontaneously express neural proteins in culture and are neurogenic after transplantation. Stem Cells. 2006; 24(4):1054-1064.

76. Kamishina H, Deng J, Oji T, et al. Expression of neural markers on bone marrow-derived canine mesenchymal stem cells. Am J Vet Res. 2006;67(11):1921-1928.

77. Chung CS, Fujita N, Kawahara N, Yui S, Nam E, Nishimura R. A comparison of neurosphere differentiation potential of canine bone marrowderived mesenchymal stem cells and adipose-derived mesenchymal stem cells. J Vet Med Sci. 2013;75:879-886.

78. Kim EY, Lee KB, Yu J, et al. Neuronal cell differentiation of mesenchymal stem cells originating from canine amniotic fluid. Hum Cell. 2014;27(2):51-58.

79. Nakano R, Edamura K, Nakayama T, et al. Differentiation of canine bone marrow stromal cells into voltage- and glutamate-responsive neuronlike cells by basic fibroblast growth factor. J Vet Med Sci. 2015;77(1): 27-35.
80. $\mathrm{Hu} \mathrm{H}, \mathrm{Ni} \mathrm{Y}$, Montana V, et al. Chemically functionalized carbon nanotubes as substrates for neuronal growth. Nano Lett. 2004;4(3): 507-511.

81. Cellot G, Cilia E, Cipollone S, et al. Carbon nanotubes might improve neuronal performance by favouring electrical shortcuts. Nat Nanotechnol. 2008;4:126-133.

82. Lee JH, Lee J-Y, Yang SH, et al. Carbon nanotube-collagen threedimensional culture of mesenchymal stem cells promotes expression of neural phenotypes and secretion of neurotrophic factors. Acta Biomater. 2014;10(10):4425-4436.

83. Cho Y, Choi JS, Jeong SY, Yoo HS. Nerve growth factor (NGF)conjugated electrospun nanostructures with topographical cues for neuronal differentiation of mesenchymal stem cells. Acta Biomater. 2010;6(12):4725-4733.

84. Heo JS, Choi SM, Kim H, et al. Neural transdifferentiation of human bone marrow mesenchymal stem cells on hydrophobic polymermodified surface and therapeutic effects in an animal model of ischemic stroke. Neuroscience. 2013;238:305-318.

85. Dahlstrand J, Zimmerman L, McKay R, Lendahl U. Characterization of human nestin gene reveals a close evolutionary relationship to neurofilaments. J Cell Sci. 1992;103(pt 2):589-597.

86. Lendahl U, Zimmerman LB, McKay RD. CNS stem cells express a new class of intermediate filament protein. Cell. 1990;60(4):585-595.

87. Jan E, Kotov NA. Successful differentiation of mouse neural stem cells on layer-by-layer assembled single-walled carbon nanotube composite. Nano Lett. 2007;7(5):1123-1128.
International Journal of Nanomedicine

\section{Publish your work in this journal}

The International Journal of Nanomedicine is an international, peerreviewed journal focusing on the application of nanotechnology in diagnostics, therapeutics, and drug delivery systems throughout the biomedical field. This journal is indexed on PubMed Central, MedLine, CAS, SciSearch ${ }^{\circledR}$, Current Contents ${ }^{\circledR} /$ Clinical Medicine,

\section{Dovepress}

Journal Citation Reports/Science Edition, EMBase, Scopus and the Elsevier Bibliographic databases. The manuscript management system is completely online and includes a very quick and fair peer-review system, which is all easy to use. Visit http://www.dovepress.com/ testimonials.php to read real quotes from published authors. 